\title{
Correlation of phenotype with genotype and protein structure in RYR1-related disorders
}

\author{
Joshua J. Todd ${ }^{1} \cdot$ Vatsala Sagar $^{2} \cdot$ Tokunbor A. Lawal $^{1} \cdot$ Carolyn Allen $^{1} \cdot$ Muslima S. Razaqyar ${ }^{1} \cdot$ Monique S. Shelton $^{1}$. \\ Irene C. Chrismer ${ }^{1} \cdot$ Xuemin Zhang $^{1} \cdot$ Mary M. Cosgrove ${ }^{1} \cdot$ Anna Kuo $^{1} \cdot$ Ruhi Vasavada $^{3} \cdot$ Minal S. Jain $^{3}$. \\ Melissa Waite $^{3} \cdot$ Dinusha Rajapakse $^{2} \cdot$ Jessica W. Witherspoon ${ }^{1} \cdot$ Graeme Wistow $^{2} \cdot$ Katherine G. Meilleur $^{1}$
}

Received: 28 July 2018 / Revised: 17 August 2018 / Accepted: 18 August 2018 / Published online: 28 August 2018

(c) The Author(s) 2018

\begin{abstract}
Variants in the skeletal muscle ryanodine receptor 1 gene $(R Y R I)$ result in a spectrum of $R Y R I$-related disorders. Presentation during infancy is typical and ranges from delayed motor milestones and proximal muscle weakness to severe respiratory impairment and ophthalmoplegia. We aimed to elucidate correlations between genotype, protein structure and clinical phenotype in this rare disease population. Genetic and clinical data from 47 affected individuals were analyzed and variants mapped to the cryo-EM RyR1 structure. Comparisons of clinical severity, motor and respiratory function and symptomatology were made according to the mode of inheritance and affected RyR1 structural domain(s). Overall, 49 RYRl variants were identified in 47 cases (dominant/de novo, $n=35$; recessive, $n=12$ ). Three variants were previously unreported. In recessive cases, facial weakness, neonatal hypotonia, ophthalmoplegia/paresis, ptosis, and scapular winging were more frequently observed than in dominant/de novo cases (all, $p<0.05$ ). Both dominant/de novo and recessive cases exhibited core myopathy histopathology. Clinically severe cases were typically recessive or had variants localized to the RyR1 cytosolic shell domain. Motor deficits were most apparent in the MFM-32 standing and transfers dimension, [median (IQR) 85.4 (18.8)\% of maximum score] and recessive cases exhibited significantly greater overall motor function impairment compared to dominant/de novo cases [79.7 (18.8)\% vs. 87.5 (17.7)\% of maximum score, $p=0.03$ ]. Variant mapping revealed patterns of clinical severity across RyR1 domains, including a structural plane of interest within the RyR1 cytosolic shell, in which $84 \%$ of variants affected the bridging solenoid. We have corroborated genotype-phenotype correlations and identified RyR 1 regions that may be especially sensitive to structural modification.
\end{abstract}

Keywords Genotype-phenotype $\cdot$ Structure-function $\cdot$ RyR1 $\cdot$ Neuromuscular disease $\cdot$ Myopathy

\section{Introduction}

Electronic supplementary material The online version of this article (https://doi.org/10.1007/s00415-018-9033-2) contains supplementary material, which is available to authorized users.

Joshua J. Todd

joshua.todd@nih.gov

1 Neuromuscular Symptoms Unit, Tissue Injury Branch, National Institute of Nursing Research, National Institutes of Health, 10 Center Drive, Room 2A07, Bethesda, MD 20892, USA

2 Section on Molecular Structure and Functional Genomics, National Eye Institute, National Institutes of Health, Bethesda, MD, USA

3 Mark O. Hatfield Clinical Research Center, Rehabilitation Medicine Department, National Institutes of Health, Bethesda, MD, USA
First described as a single entity in 1956 [43], congenital myopathies are now considered a spectrum of rare, slowlyprogressive neuromuscular disorders with overlapping symptoms and histopathology [31]. Congenital myopathies have been attributed to pathogenic variants in over 20 genes. Of these, RYRI-related disorders (RYRI-RD) are the most frequent, identified in $90 \%$ of central core disease (CCD) patients, and with a pediatric incidence of at least 1:90,000 within the United States [3, 10, 89]. RYRI (19q 13.2) contains 106 exons and encodes the skeletal muscle isoform of the largest known ion channel in humans, RyR1 [89]. An autosomal dominant/de novo (AD/DN) mode of inheritance is most frequently associated with malignant hyperthermia susceptibility (MHS) whereas autosomal recessive (AR) 
cases often present with a more severe clinical phenotype from birth. However, malignant hyperthermia (MH) crises have also been reported, albeit less often, in AR cases and therefore all RYRI-RD affected individuals should be considered as potentially susceptible $[1,33,40]$. Disease manifestations include delayed motor milestones, proximal/axial muscle weakness, hypotonia, scoliosis and, in more severe cases, ophthalmoplegia and respiratory insufficiency [87]. RYRI-RD subtypes have classically been defined according to skeletal muscle histopathology. Examples include CCD, multi-minicore disease $(\mathrm{MmD})$, centronuclear myopathy (CNM), core-rod myopathy (CRM), and congenital fibertype disproportion (CFTD) [53]. However, these histopathological features are not unique to $R Y R I-\mathrm{RD}$, and are variable over time. In addition, there is an expanding spectrum of $R Y R 1$-associated clinical phenotypes, including $R Y R I$ rhabdomyolysis-myalgia syndrome, atypical periodic paralysis, and King-Denborough syndrome [15, 48, 88].

Forming an exceptionally large, 2.2 MDa homotetramer, RyR1 is localized to the sarcoplasmic reticulum (SR) of skeletal muscle and functions to release sarcoplasmic calcium $\left(\mathrm{Ca}^{2+}\right)$ stores into the cytosol upon depolarization of the neuromuscular junction, enabling excitation-contraction coupling [77]. The largest RyR1 domain is the cytosolic shell (CS), also referred to as the RyR1 foot region, which constitutes the first 3613 amino acid residues and is immersed in the intracellular myoplasm [13]. The CS forms crucial inter-subunit interactions and houses the binding sites for the channel activity regulatory proteins calmodulin, S100A1 and the 12-kDa FK506-binding protein (FKBP12) [24, 57, 92]. The remaining 1423 residues constitute the channel and activation core (CAC) domain, through which $\mathrm{SR} \mathrm{Ca}^{2+}$ efflux occurs and where $\mathrm{Ca}^{2+}$, ryanodine, and adenosine triphosphate (ATP) bind at the zinc finger-containing C-terminal region [13]. Importantly, rather than directly triggering RyR1 opening, binding of agonists such as $\mathrm{Ca}^{2+}$, ATP, and caffeine shift RyR1 into a primed state by decreasing the energetic resistance of specific $\mathrm{CAC}$ regions that are collectively termed the "activation module" [13]. In recent years, functional studies have shed light on the mechanistic consequence of specific $R Y R I$ variants, although these constitute $<10 \%$ of almost 700 known $R Y R I$ variants [28, 40]. Variants associated with $R Y R I-\mathrm{RD}$ have been identified throughout the $R Y R l$ coding and intronic regions and can lead to chronic SR Ca ${ }^{2+}$ leak, decreased RyR1 protein levels, and RyR1 hyper- or hypo-sensitivity to agonists such as 4-chloro- $m$-cresol and caffeine [71, 72, 83, 95].

The last prospective genotype-phenotype assessment of $R Y R I-\mathrm{RD}$, which encompassed $\mathrm{AD} / \mathrm{DN}$ and $\mathrm{AR}$ cases, was published over a decade ago and provided excellent insight at that time [93]. Nevertheless, numerous additional clinical phenotypes have since emerged onto the $R Y R I-R D$ disease spectrum, and our understanding of genotype-phenotype correlations has continued to evolve. Moreover, recent cryo-electron microscopy (cryo-EM) breakthroughs have elucidated the molecular RyR1 structure at near-atomic resolution, which has modified our understanding of established structural regions [13, 89]. Here, we use the latest cryo-EM domain/region terminology [13]. More precise localization of critical modulatory protein binding sites has also been achieved. These include sites for FKBP12 at the interface of several regions termed the bridging solenoid (Bsol), SP1a/ryanodine receptor domain 1 (SPRY1), and SP1a/ryanodine receptor domain 2 (SPRY2) regions $[65,91]$. Whilst studies have revealed that AR cases are typically more clinically severe, less is known about the impact of variant location on channel function and the resulting clinical phenotype.

Using prospective data obtained from 47 RYR I-RD affected individuals; we sought to elucidate the complex genotype-phenotype and protein structure-phenotype relationships of this rare disease, for which there is currently no approved treatment. A detailed genotype-phenotype relationship is provided by mode of inheritance, and an assessment of clinical manifestations and severity is also made according to the affected RyR1 structural domain(s). In total, 46 variants in the RYRI coding region and 3 at intronic/splice sites are discussed; the former are mapped to the latest cryoEM RyR1 structure and presented alongside published functional assay results.

\section{Materials and methods}

\section{Participants}

A total of 47 individuals [males, $n=20(43 \%)$; adults, $n=31(66 \%)$ ] enrolled in a combined natural history study and double-blind, randomized, placebo-controlled trial with $N$ acetylcysteine, for RYRI-RD (NCT02362425). The sample size in the cross-sectional analysis presented here was determined by a power calculation performed for the aforementioned clinical trial. Participants were recruited through advertisements, neuromuscular clinician referral, and patient advocacy group outreach. Study procedures were approved by a National Institutes of Health (NIH) Institutional Review Board, and participants provided informed consent or assent, in accordance with the Declaration of Helsinki, before enrollment. The study was conducted at the NIH Clinical Center, Bethesda, MD, USA, between March 2015 and November 2017 and consisted of a 6-month natural history assessment and 6-month intervention. For the crosssectional analysis presented here, data were obtained from participants at baseline. Inclusion and exclusion criteria are detailed at: NCT02362425. 


\section{RYR1 sequencing and variant screening}

Diagnostic genetic testing reports were obtained from individuals' medical records. Genetic testing was conducted at laboratories certified to the Clinical Laboratory Improvement Amendments (CLIA) standards, or non-U.S equivalent. Alamut Visual (version 2.9.0, Interactive Biosoftware, Rouen, France), was used to confirm RYRl variants specified in genetic testing reports, generate orthologue alignments, and identify previously reported variants. For missense substitutions, differences in physico-chemical properties between wild-type and mutant amino acids were also estimated using Alamut Visual [19, 67, 74]. Three-generation family histories and parental genetic testing reports, when available, were obtained from participants to confirm the mode of inheritance. When this was not possible, a plausible mode of inheritance was established through careful evaluation of clinical manifestations characteristic of AR cases [2].

\section{Physical examination and clinical severity grading}

A single Nurse Practitioner administered all physical examinations for study participants. This included assessment of the following systems: head, ears, eyes, nose and throat, neurologic, respiratory, cardiovascular, gastrointestinal, genitourinary, endocrine, hematologic, immune, dermatologic, psychiatric, and musculoskeletal health. Distal and proximal weakness was ascertained by manual muscle testing and were defined as two or more $\leq 4$ grade responses. Heat and exercise tolerance were determined using both the participant's medical record and self-reported medical history the time of study enrolment. Clinical severity was determined using an RYRI-RD 8-point scale focused on ambulatory and respiratory function [2].

\section{Skeletal muscle histopathology}

Skeletal muscle histopathology reports were obtained from participants' medical records. Reports were available for 26/47 participants. Each panel typically included histology: NADH tetrazolium reductase (NADH-TR), hematoxylin and eosin (HE), Gömöri Trichrome (GO), periodic acidSchiff (PAS), Oil-Red O (ORO); histo-enzymology staining: cytochrome oxidase (COX), succinate dehydrogenase (SDH), ATPase; and immunohistochemistry: myosin isoform (slow and fast heavy chain).

\section{Assessment of respiratory function}

Pulmonary function tests (PFTs) were conducted by a physical therapist in accordance with American Thoracic Society (ATS) guidelines [35]. PFTs included forced vital capacity (FVC), forced expiratory volume at $1 \mathrm{~s}\left(\mathrm{FEV}_{1}\right), \mathrm{FVC}$ to
$\mathrm{FEV}_{1}$ ratio, and slow vital capacity (SVC). Percent predicted values for PFTs were calculated using BreezeSuite software (CPFS/D USB spirometer, MGC Diagnostics, Saint Paul, MN, USA). Thresholds of $<80$ and $<60 \%$ predicted FVC were used to define respiratory insufficiency and moderate respiratory insufficiency, respectively [25, 82]. Participants on BiPAP or CoughAssist were also categorized as having impaired respiratory function.

\section{Motor function measure (MFM-32) assessment}

Motor function was evaluated using MFM-32 which has been developed and validated for use in the neuromuscular disease population, including $R Y R I-\mathrm{RD}[80,81]$. This was completed for each participant by physical therapists. MFM32 consists of three dimensions that account for posture and whole-body movements related to standing and transfers (dimension 1), axial and proximal motor function (dimension 2), and distal motor function (dimension 3). Data were expressed as a percentage of the maximum possible score for each dimension as well as an overall total score.

\section{Variant mapping}

Variant analysis and graphical representation were performed with Pymol software (version 2.0.4; Schrödinger, LLC, NY) using PDB (Protein Data Bank; [6]) structure PDB: 5TAX open state. All RYRl coding-region variants identified in this cohort $(n=46)$ were mapped to the RyR1 monomer based on domain location, except stop-gain (premature termination), synonymous substitution, and frameshift variants $(n=8)$, and those affecting unassigned residues $(n=2)$. Variants were further mapped based on clinical severity using the abovementioned scale. Variants associated with clinically severe phenotypes were mapped in red. Variants associated with mild clinical severity (severity scores below 5) were subdivided into three categories: orange (severity score of 3-4), green (severity score of 1-2), and white (severity score of 0 ). When multiple cases were associated with a specific variant, an average clinical severity score was calculated, to the nearest whole number.

\section{Statistics}

All statistical tests were conducted using the Statistical Package for the Social Sciences version 24 (SPSS; IBM, Armonk, NY, USA). For genotype-phenotype comparisons, participants were grouped based on mode of inheritance; AD/DN or AR. For structure-phenotype comparisons, cryo-EM-defined residue spans for RyR1 structural domains [13], were used to group participants based on whether RYRI variant(s) were located in the (a) only the RyR1 CS domain, (b) only the RyR1 CAC domain, or (c) 
both domains. Descriptive statistics were generated for each group and data distribution was assessed using the Shapiro-Wilk test. MFM-32 and age at diagnosis data were skewed, therefore Mann-Whitney $U$ test or Kruskal-Wallis with Dunn's post-hoc test were used to identify statistically significant differences between groups. Data for PFTs followed a Gaussian distribution, therefore differences between groups were assessed by ANOVA with Bonferroni post-hoc test or independent $t$ test. Fisher's Exact test was used to compare the proportion of clinically severe cases (severity score $\geq 5$ ) by mode of inheritance, by affected RyR 1 domain(s), and the proportion of cases that exhibited moderate respiratory insufficiency, by mode of inheritance and affected RyR1 domain(s).

\section{Results}

In this cohort, 49 variants were identified, with 46 located in the RYRI coding region and three at intronic/splice sites (Table 1). Three variants (p.Asn4575Thr, p.Met4840Arg, and p.Met4875Val) were novel (i.e., not reported in ExAC/ gnomAD, ESP, HGVD, ClinVar, 1000 Genomes, or HGMD databases and not published to date). An AD/DN mode of inheritance was most frequent (35/47 cases), and all AR cases were compound heterozygous. In this cohort, variants affected the following RyR1 domain(s): only the CS $n=12$ cases; only the CAC $n=29$; both domains $n=6$ cases. Summary demographics are provided in Table 2. For participants born before the advent of massively parallel (next generation) sequencing in $2004(n=35)$ [79], the median (IQR) age of $R Y R 1$-RD diagnosis was 36.0 (23.4) years compared to 4.5 (3.8) years in those born after 2004, $p<0.001$. Structural and functional data for each variant are detailed in Table 3. There was no difference in clinical severity scores between males $(n=20)$ versus females $(n=27)$, (average clinical severity score $=3$ for both groups, $p=0.139)$.

\section{Genotype-phenotype correlation and histopathology}

RYRl coding region variants predominantly consisted of missense substitutions (36/46); 89.1\% of which affected highly evolutionarily conserved positions (Figs. S1 and S2). Other variant types included stop-gain substitution $(n=3)$, synonymous substitution $(n=1)$, deletion leading to stop-gain $(n=1)$, frame-shift deletion/duplication/insertion $(n=3)$, deletion-insertion $(n=1)$, and in-frame deletion $(n=1)$. Three intronic substitutions were identified, two of which were canonical splice site variants (c.8933-1 G > A and c. $9001-2 \mathrm{~A}>\mathrm{G}$ ). In $94 \%$ of the cohort, $R Y R 1$ variant(s) were identified within one or more of the three established $\mathrm{MH} / \mathrm{CCD}$ hot spot regions [89]. Variant distribution across the RYRI coding region, including $\mathrm{MH} / \mathrm{CCD}$ hot spot regions, is depicted in Fig. 1. Multiple RYRl variants were identified in $30 \%$ of the cohort with $13 \%$ of these participants possessing variants that affected both RyR1 domains. There was no difference in the proportion of clinically severe cases (severity score $\geq 5$ ), by mode of inheritance (AD/AR $11 \%$ versus AR $25 \%, p=0.35$ ), Fig. S3A.

Overall, $73 \%$ of participants with histopathology reports $(n=26)$ had evidence of cores, Fig. S4. AD/DN cases with biopsy results $(n=16)$ were associated with $\mathrm{CCD} / \mathrm{MmD}$ pathology $88 \%$ of the time with the remaining $12 \%$ exhibiting either no pathology or inconclusive biopsy results. Of note, the single case (case 39) for which no histopathology was evident on biopsy, exhibited a recurrent rhabdomyolysis-myalgia clinical phenotype. In AR cases with histopathology reports available $(n=10)$, biopsy findings were more diverse, however, $\mathrm{CCD} / \mathrm{MmD}$ pathology was still most frequently observed ( $40 \%$ of cases), followed by congenital fiber-type disproportion ( $30 \%$ of cases).

The overall median (IQR) MFM-32 result for this cohort (\% maximum score) was as follows: standing and transfers 66.7 (35.5)\%; axial and proximal motor function 100.0 (5.6)\%; distal motor function 95.2 (9.5)\%; total score 85.4 (18.8)\%. With the exception of standing and transfers, AR cases achieved significantly lower MFM-32 score across all other MFM-32 dimensions, compared to AD/DN cases [standing and transfers, 59.0 (27.6)\% vs. 71.8 (33.3)\% $p=0.078$; axial and proximal motor function, $97.2(16.0) \%$ vs. $100.0(19.1) \% p=0.017$; distal motor function, 92.9 (8.3)\% vs. 95.2 (4.8)\% $p=0.046$; total score, 79.7 (18.8)\% vs. $87.5(17.7) \% p=0.037]$, Fig. 2 a.

Two AR cases were unable to perform PFTs owing to tracheostomy and inability to meet all PFT standardization criteria (cases 10 and 12, respectively). Overall, 38\% of the cohort exhibited respiratory insufficiency (FVC $<80 \%$ predicted) with $13 \%$ demonstrating moderate respiratory insufficiency ( $\mathrm{FVC}<60 \%$ ). There was no difference in PFT results according to the mode of inheritance (all, $p>0.05$ ), Fig. 2b and Fig. S5a, b.

Clinical findings for each participant are provided in Table S1. The most frequently observed clinical manifestations in this cohort were delayed motor milestones and proximal skeletal muscle weakness (both observed in $87 \%$ of cases), followed by skeletal muscle atrophy (observed in $79 \%$ of cases), abnormal gait, and facial weakness (both observed in $77 \%$ of cases). In AR cases, facial weakness, neonatal hypotonia, ophthalmoplegia/paresis, ptosis, and scapular winging were more frequently observed than in $\mathrm{AD} /$ DN cases (all, $p<0.05$ ), Fig. 3a. Of note, Ophthalmoplegia/ paresis was only observed in AR cases (42\%). In contrast, hypotonia, and delayed motor milestones were frequently observed regardless of the mode of inheritance (70-100\% of cases, both $p>0.05$ ). MHS or a pertinent family history for 
Table 1 Genetic details of RYRI-RD affected individuals

\begin{tabular}{|c|c|c|c|c|c|c|}
\hline Case:Family & Exon/intron & Nucleotide change & Amino acid change & Mode of inheritance & Variant classification $^{\mathrm{a}}$ & Reported in \\
\hline \multicolumn{7}{|c|}{ Participants with variant(s) affecting only the RyR1 cytosolic shell } \\
\hline $1: 1$ & E 46 & c. $7354 \mathrm{C}>\mathrm{T}$ & p.Arg2452Trp & Dominant & Pathogenic & {$[61]$} \\
\hline $2: 1$ & E 46 & c. $7354 \mathrm{C}>\mathrm{T}$ & p.Arg2452Trp & Dominant & & \\
\hline \multirow[t]{2}{*}{$3: 2$} & E 10 & c. $838 \mathrm{C}>\mathrm{T}$ & p.Arg $280 *$ & Recessive & VUS & [77] \\
\hline & E 66 & c. $9716 \mathrm{~T}>\mathrm{A}$ & p.Met3239Lys & & VUS & [77] \\
\hline $4: 3$ & E 41 & c. $6697 \mathrm{~T}>\mathrm{C}$ & p.Cys2233Arg & Dominant & VUS & [77] \\
\hline \multirow[t]{4}{*}{$5: 4$} & E 41 & c. $6721 \mathrm{C}>\mathrm{T}$ & p.Arg $2241^{*}$ & Recessive & Pathogenic & [27] \\
\hline & E 4 & c. $325 \mathrm{C}>\mathrm{T}$ & p.Arg109Trp & & Likely pathogenic & {$[95]$} \\
\hline & E 18 & c. $2122 \mathrm{G}>\mathrm{A}$ & p.Asp708Asn & & VUS & {$[86]$} \\
\hline & E 14 & c. $1453 \mathrm{~A}>\mathrm{G}$ & p.Met485Val & & VUS & [95] \\
\hline $6: 5$ & E 39 & c. $6488 \mathrm{G}>\mathrm{A}$ & p.Arg2163His & Dominant & Pathogenic & [45] \\
\hline \multirow[t]{3}{*}{$7: 6$} & E 15 & c. $1589 \mathrm{G}>\mathrm{A}$ & p.Arg530His & Recessive & VUS & [96] \\
\hline & E 24 & c. $3127 \mathrm{C}>\mathrm{T}$ & p.Arg1043Cys & & VUS & {$[96]$} \\
\hline & E 43 & c. $7007 \mathrm{G}>\mathrm{A}$ & p.Arg2336His & & VUS & [7] \\
\hline $8: 7$ & E 24 & c. $2923 \mathrm{C}>\mathrm{T}$ & p.Arg975Trp & Dominant & VUS & [9] \\
\hline $9: 7$ & E 24 & c. $2923 \mathrm{C}>\mathrm{T}$ & p.Arg975Trp & Dominant & & \\
\hline \multirow[t]{2}{*}{$10: 8$} & E 44 & c.7166_7176del11 & p.Asp2389Glyfs*16 & Clinically recessive ${ }^{b}$ & Likely pathogenic & [77] \\
\hline & I 58 & c. $8933-1 \mathrm{G}>\mathrm{A}$ & (intronic) & & Likely pathogenic & [76] \\
\hline \multirow[t]{2}{*}{$11: 9$} & E 31 & c.4485_4500del16 & p.Trp1495* & Recessive & Pathogenic & [8] \\
\hline & E 44 & c.7060_7062delGTG & p.Val2354del & & Likely pathogenic & {$[8]$} \\
\hline \multirow[t]{2}{*}{$12: 10$} & E 40 & c. $6617 \mathrm{C}>\mathrm{T}$ & p.Thr2206Met & Recessive & Pathogenic & {$[62]$} \\
\hline & I 59 & c. $9001-2 \mathrm{~A}>\mathrm{G}$ & (intronic) & & VUS & [70] \\
\hline \multicolumn{7}{|c|}{ Participants with variant(s) affecting only the RyR1 channel and activation core } \\
\hline $13: 11$ & E 94 & c. $13724 \mathrm{~A}>\mathrm{C}$ & p.Asn4575Thr & Dominant & VUS & This manuscript \\
\hline $14: 12$ & E 102 & c. $14763 \mathrm{C}>\mathrm{G}$ & p.Phe4921Leu & Dominant & VUS & {$[77]$} \\
\hline $15: 13$ & E 102 & c. $14693 \mathrm{~T}>\mathrm{C}$ & p.Ile4898Thr & Dominant & Pathogenic & [23] \\
\hline $16: 13$ & E 102 & c. $14693 \mathrm{~T}>\mathrm{C}$ & p.Ile4898Thr & Dominant & & \\
\hline $17: 14$ & E 103 & c. $14818 \mathrm{G}>\mathrm{A}$ & p.Ala4940Thr & Dominant & Pathogenic & [59] \\
\hline $18: 14$ & E 103 & c. $14818 \mathrm{G}>\mathrm{A}$ & p.Ala4940Thr & Dominant & & \\
\hline $19: 15$ & E 103 & c. $14818 \mathrm{G}>\mathrm{A}$ & p.Ala4940Thr & Dominant & & \\
\hline 20:16 & E 100 & c. $14458 \mathrm{G}>\mathrm{A}$ & p.Gly4820Arg & Dominant & VUS & [36] \\
\hline $21: 16$ & E 100 & c. $14458 \mathrm{G}>\mathrm{A}$ & p.Gly4820Arg & Dominant & & \\
\hline $22: 16$ & E 100 & c. $14458 \mathrm{G}>\mathrm{A}$ & p.Gly4820Arg & Dominant & & \\
\hline $23: 17$ & E 101 & c. $14582 \mathrm{G}>\mathrm{A}$ & p.Arg4861His & Dominant & Pathogenic & {$[70]$} \\
\hline $24: 17$ & E 101 & c. $14582 \mathrm{G}>\mathrm{A}$ & p.Arg4861His & Dominant & & \\
\hline $25: 18$ & E 101 & c. $14582 \mathrm{G}>\mathrm{A}$ & p.Arg4861His & Dominant & & \\
\hline $26: 19$ & E 101 & c. $14582 \mathrm{G}>\mathrm{A}$ & p.Arg4861His & Dominant & & \\
\hline $27: 20$ & E 101 & c. $14582 \mathrm{G}>\mathrm{A}$ & p.Arg4861His & Dominant & & \\
\hline $28: 21$ & E102 & c. $14678 \mathrm{G}>\mathrm{A}$ & p.Arg4893Gln & Dominant & Pathogenic & {$[12]$} \\
\hline $29: 21$ & E102 & c. $14678 \mathrm{G}>\mathrm{A}$ & p.Arg4893Gln & Dominant & & \\
\hline $30: 22$ & E 102 & c. $14681 C>A$ & p.Ala4894Asp & Dominant & VUS & {$[77]$} \\
\hline $31: 22$ & E 102 & c. $14681 \mathrm{C}>\mathrm{A}$ & p.Ala4894Asp & Dominant & & \\
\hline \multirow[t]{2}{*}{$32: 23$} & E 101 & c. $14582 \mathrm{G}>\mathrm{A}$ & p.Arg4861His & Clinically dominant ${ }^{\mathrm{b}}$ & Pathogenic & {$[69]$} \\
\hline & E 91 & c.13331_13351dup & p.Gly4444- & & VUS & gnomAD\# 19:39056300 \\
\hline $33: 24$ & E 103 & c. $14807 \mathrm{~T}>\mathrm{G}$ & p.Leu4936Arg & Dominant & VUS & [2] \\
\hline \multirow[t]{3}{*}{$34: 25$} & E 98 & c. $14210 \mathrm{G}>\mathrm{A}$ & p.Arg4737Gln & Clinically recessive $\mathrm{e}^{\mathrm{b}}$ & Pathogenic & {$[17]$} \\
\hline & E 88 & c.12063_12064dupCA & p.Met4022Thrfs*4 & & VUS & LOVD\# 0030253 \\
\hline & I 41 & c. $6797-9 \mathrm{C}>\mathrm{T}$ & (intronic) & & Likely benign & dbSNP\# 191934693 \\
\hline $35: 26$ & E 88 & c. $12083 \mathrm{C}>\mathrm{T}$ & p.Ser4028Leu & Dominant & VUS & [11] \\
\hline $36: 27$ & E 100 & c.14422_14423delTTinsAA & p.Phe4808Asn & Dominant & Likely pathogenic & [12] \\
\hline $37: 28$ & E 101 & c. $14558 \mathrm{C}>\mathrm{T}$ & p.Thr4853Ile & Dominant & Pathogenic & [21] \\
\hline $38: 29$ & E 102 & c. $14731 \mathrm{G}>\mathrm{A}$ & p.Glu4911Lys & Dominant & Pathogenic & [7] \\
\hline $39: 30$ & E 92 & c. $13513 \mathrm{G}>\mathrm{C}$ & p.Asp4505His & Dominant & VUS & {$[11]$} \\
\hline $40: 30$ & E 92 & c. $13513 \mathrm{G}>\mathrm{C}$ & p.Asp4505His & Dominant & & \\
\hline $41: 30$ & E 92 & c. $13513 \mathrm{G}>\mathrm{C}$ & p.Asp4505His & Dominant & & \\
\hline
\end{tabular}


Table 1 (continued)

\begin{tabular}{|c|c|c|c|c|c|c|}
\hline Case:Family & Exon/intron & Nucleotide change & Amino acid change & Mode of inheritance & Variant classification $^{\mathrm{a}}$ & Reported in \\
\hline \multicolumn{7}{|c|}{ Participants with variant(s) affecting both the RyR1 cytosolic shell and channel and activation core } \\
\hline \multirow[t]{2}{*}{$42: 31$} & E 43 & c. $7025 \mathrm{~A}>\mathrm{G}$ & p.Asn2342Ser & Recessive & VUS & [46] \\
\hline & E 101 & c. $14519 \mathrm{~T}>\mathrm{G}$ & p.Met4840Arg & & VUS & This manuscript \\
\hline \multirow[t]{4}{*}{ 43:29 } & E 102 & c. $14731 \mathrm{G}>\mathrm{A}$ & p.Glu4911Lys & Recessive & Pathogenic & [33] \\
\hline & E 33 & c. $4711 \mathrm{~A}>\mathrm{G}$ & p.Ile1571Val & & VUS & [70] \\
\hline & E 67 & c. $10097 \mathrm{G}>\mathrm{A}$ & p.Arg3366His & & VUS & [73] \\
\hline & E 86 & c. $11798 \mathrm{~A}>\mathrm{G}$ & p.Tyr3933Cys & & VUS & [7] \\
\hline \multirow[t]{2}{*}{$44: 32$} & E 41 & c. $6721 \mathrm{C}>\mathrm{T}$ & p. $\operatorname{Arg} 2241^{*}$ & Clinically recessive $^{\mathrm{b}}$ & Pathogenic & [7] \\
\hline & E 96 & c. $14126 \mathrm{C}>\mathrm{T}$ & p.Thr4709Met & & Pathogenic & [76] \\
\hline \multirow[t]{2}{*}{$45: 15$} & E 41 & c. $6671 \mathrm{G}>\mathrm{A}$ & p.Arg2224His & Recessive & VUS & dbSNP\# 537994744 \\
\hline & E 103 & c. $14818 \mathrm{G}>\mathrm{A}$ & p.Ala4940Thr & & Pathogenic & {$[59]$} \\
\hline \multirow[t]{2}{*}{$46: 33$} & E 45 & c. $7300 \mathrm{G}>\mathrm{A}$ & p.Gly2434Arg & Clinically recessive $^{\mathrm{b}}$ & Pathogenic & [14] \\
\hline & E 101 & c. $14623 \mathrm{~A}>\mathrm{G}$ & p.Met $4875 \mathrm{Val}$ & & VUS & This manuscript \\
\hline \multirow[t]{3}{*}{$47: 34$} & E26 & c. $3495 \mathrm{C}>\mathrm{T}$ & p.Gly1165Gly & Recessive & VUS & dbSNP\# 772616442 \\
\hline & E33 & c. $4817 \mathrm{G}>\mathrm{A}$ & p.Arg1606His & & VUS & dbSNP\# 368399715 \\
\hline & E90 & c. $12499 \mathrm{G}>\mathrm{T}$ & p.Glu4167* & & Pathogenic & dbSNP\# 772494345 \\
\hline
\end{tabular}

$E$ exon number, $I$ intron number, LOVD Leiden Open (source) Variation Database, $d b S N P$ single nucleotide polymorphism database, gnomAD The Genome Aggregation Database, VUS variant of uncertain significance

${ }^{\text {a }}$ Determined by genetic testing reports and validation using Alamut Visual

${ }^{\mathrm{b}}$ Such cases did not have parental genetic testing, therefore, a plausible mode of inheritance was established through careful evaluation of clinical manifestations

Table 2 Summary demographics of the RYRl-RD affected individuals

\begin{tabular}{|c|c|c|c|c|c|c|}
\hline \multirow[t]{2}{*}{ Measure } & \multirow{2}{*}{$\begin{array}{l}\text { Total cohort } \\
(n=47)\end{array}$} & \multicolumn{2}{|c|}{ Mode of inheritance } & \multicolumn{3}{|c|}{ Affected RyR1 domain(s) } \\
\hline & & $\mathrm{AD} / \mathrm{DN}(n=35)$ & $\operatorname{AR}(n=12)$ & $\mathrm{CS}(n=12)$ & $\mathrm{CAC}(n=29)$ & Both domains $(n=6)$ \\
\hline Age at enrolment, years & $28.6 \pm 17.3^{\mathrm{a}}$ & $31.7 \pm 17.2$ & $20.8 \pm 15.2$ & $29.1 \pm 17.9$ & $31.3 \pm 17.3$ & $15.2 \pm 10.3$ \\
\hline Age at $R Y R l-\mathrm{RD}$ diagnosis, years & $22.3 \pm 10.1$ & $29.1 \pm 17.9$ & $18.2 \pm 15.5$ & $26.6 \pm 18.1$ & $29.5 \pm 17.7$ & $10.7 \pm 9.5$ \\
\hline Sex, $\partial / q$ & $20: 27^{\mathrm{b}}$ & $15: 20$ & $5: 7$ & $5: 7$ & $13: 16$ & $2: 4$ \\
\hline Pediatric/adult & $16: 31$ & $10: 25$ & $6: 6$ & $4: 8$ & $8: 21$ & $4: 2$ \\
\hline Height, $\mathrm{cm}$ & $154.1 \pm 20.0$ & $156.4 \pm 19.8$ & $148.7 \pm 20.0$ & $154.4 \pm 20.2$ & $155.4 \pm 19.1$ & $147.6 \pm 25.9$ \\
\hline Weight, kg & $57.0 \pm 27.9$ & $62.4 \pm 29.1$ & $45.2 \pm 23.1$ & $62.3 \pm 32.7$ & $59.0 \pm 26.1$ & $36.8 \pm 20.0$ \\
\hline BMI, $\mathrm{kg} / \mathrm{m}^{2}$ & $22.7 \pm 8.3$ & $24.2 \pm 8.8$ & $19.2 \pm 6.0$ & $24.6 \pm 9.8$ & $23.3 \pm 7.7$ & $15.9 \pm 3.6$ \\
\hline
\end{tabular}

$A D / D N$ autosomal dominant/de novo, $A R$ autosomal recessive, $C S$ only the RyR1 CS affected, $C A C$ only the RyR1 CAC affected

${ }^{\text {a }}$ Data are expressed as mean $\pm \mathrm{SD}$

${ }^{\mathrm{b}}$ Data are expressed as frequency

MH was evident in both $\mathrm{AD} / \mathrm{DN}$ and $\mathrm{AR}$ cases $(17 \%$ and $6 \%$ of cases, respectively, $p>0.05$ ). Recurrent rhabdomyolysis was reported in a single dominant case with the proband and both male offspring all exhibiting exercise intolerance and myalgia.

\section{Structure-phenotype correlation}

Published functional assay results relating to specific variants are provided in Table 3. This table also includes details regarding whether variants are likely to impact an RyR1 functional site (e.g., triadin binding or inter-subunit interaction) and/or change amino acid composition, polarity, or molecular volume. Of the 46 coding region $R Y R l$ variants identified in this cohort, 24 affected the RyR1 CS domain and a further 22 affected the CAC domain. All missense substitution and deletion variants were mapped to the cryoEM RyR1 structure, Fig. 4C-G. The evolutionary disparity between wild-type and mutant amino acids for missense substitution variants $(n=36)$, as determined by Grantham distance (5-215), ranged from 21 to 194 with a mean distance of 76. The two canonical splice site variants (c.8933-1 $\mathrm{G}>\mathrm{A}$ and c.9001-2A $>\mathrm{G}$ ) were located adjacent to exons 59 and 60, respectively, which contribute to encoding the bridging solenoid (Bsol) in the CS domain. A greater proportion of cases, with variant(s) affecting only the RyR1 CS, were 


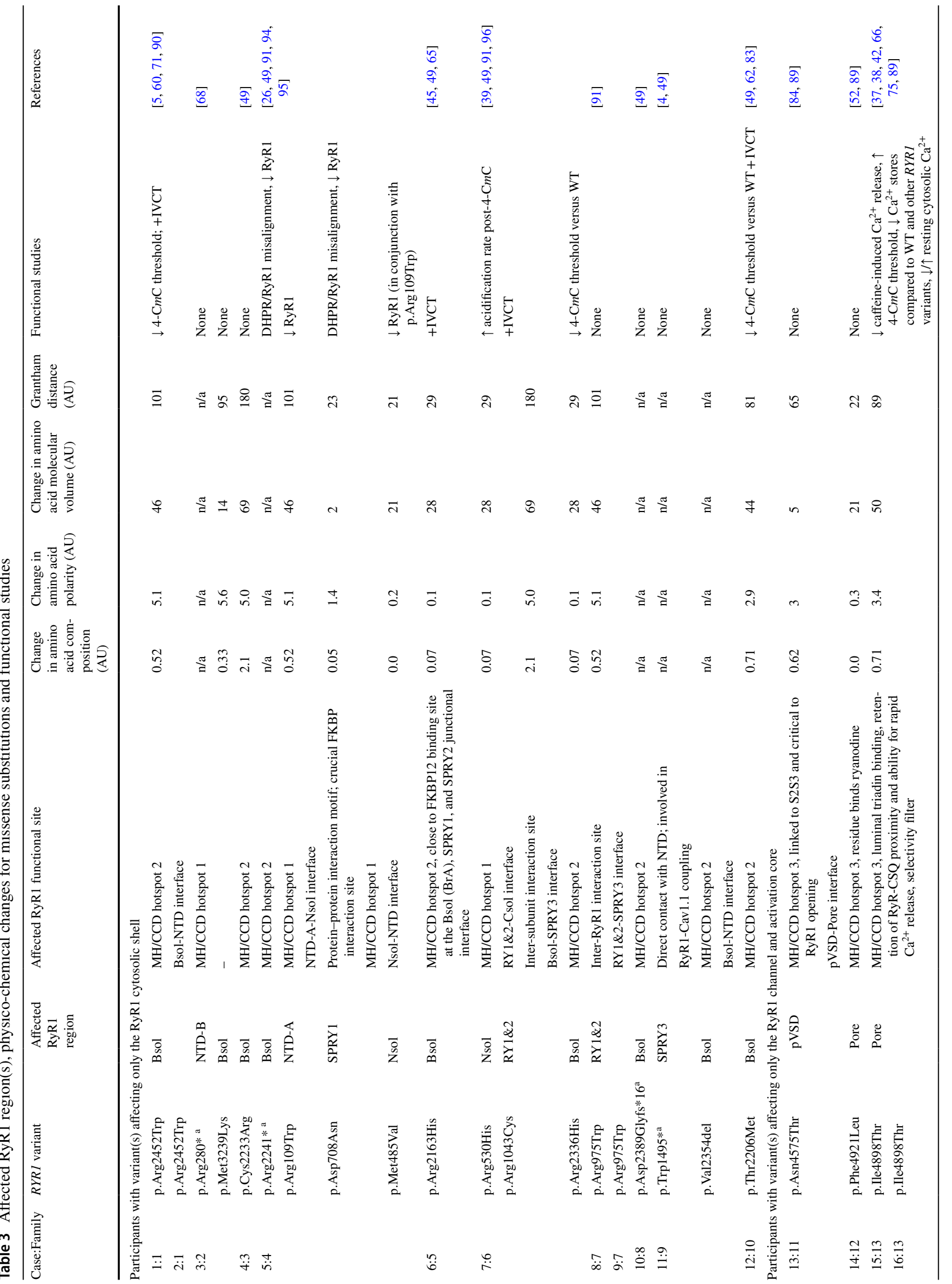




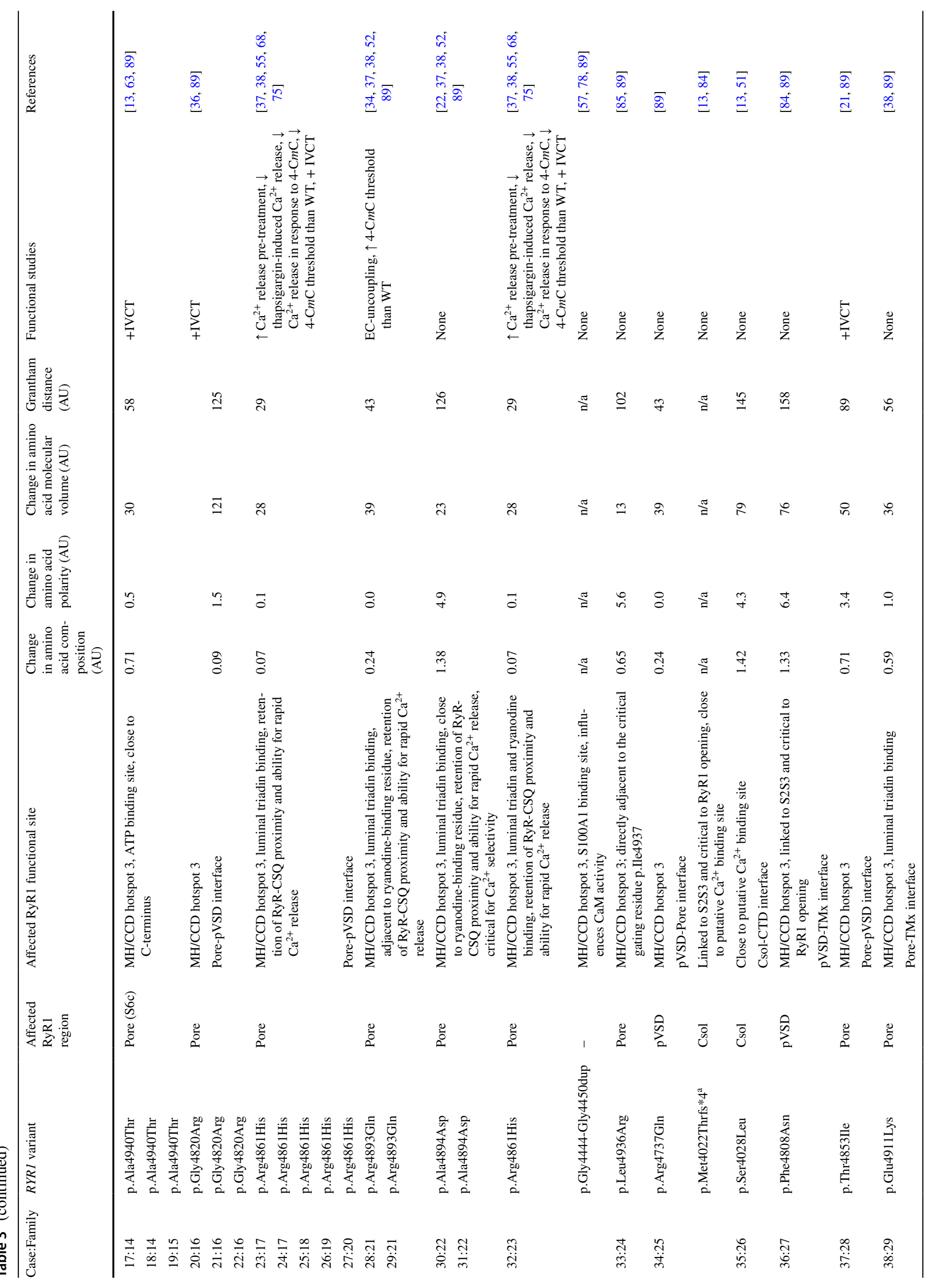




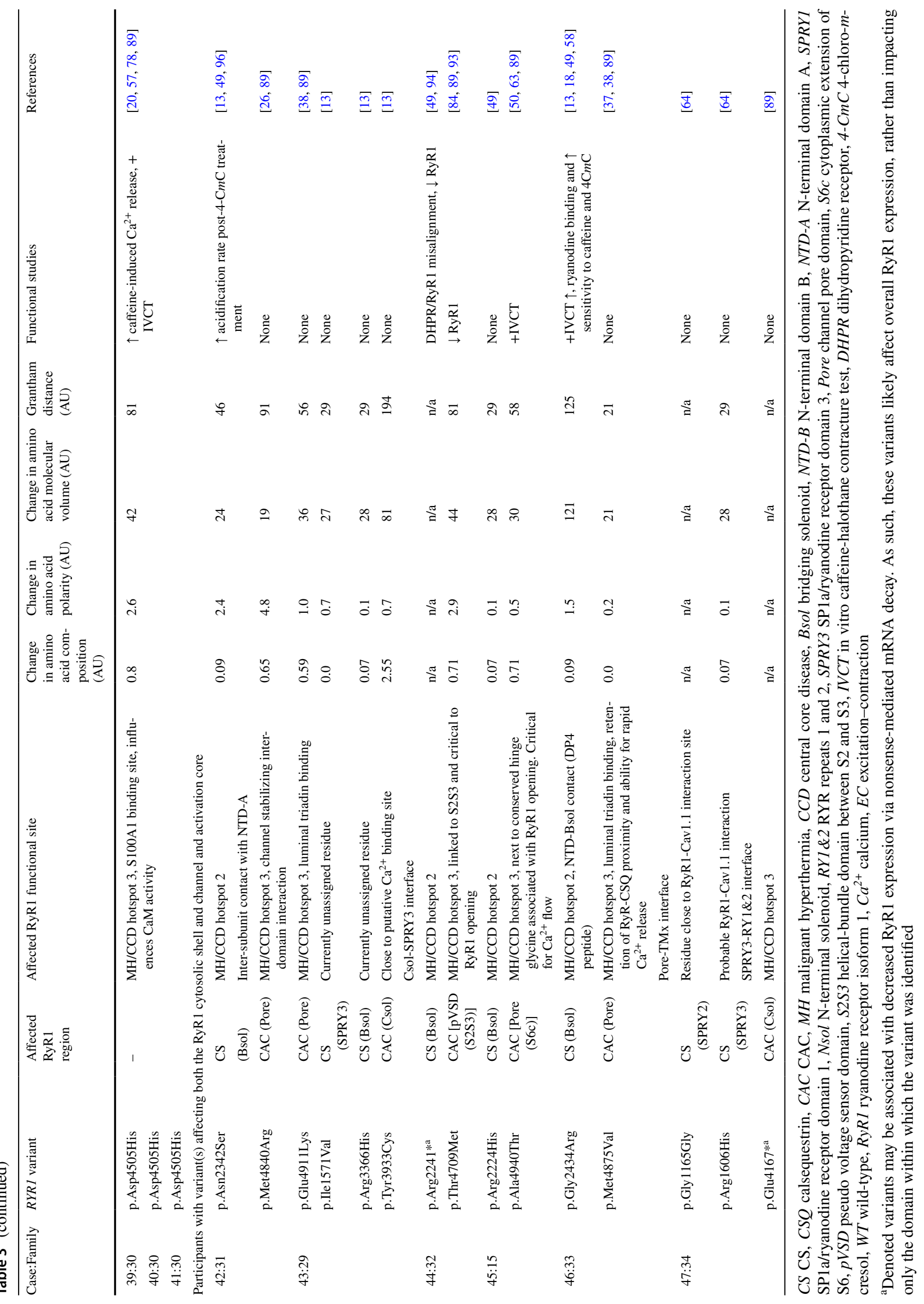



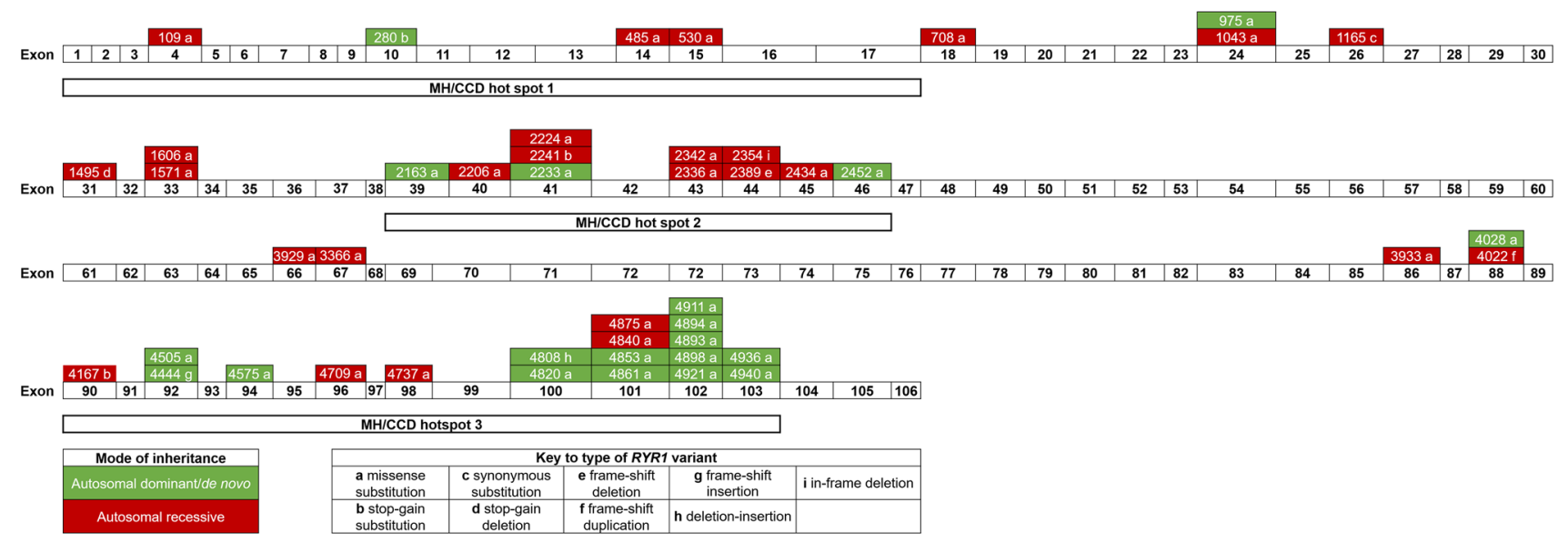

Fig. 1 Distribution of variants across the RYRl coding region including MH/CCD hot spots. Numbers within green and red boxes correspond to the affected amino acid residue

clinically severe when compared to cases with variant(s) affecting only the RyR1 CAC (33\% versus 7\% respectively, $p=0.05$ ), Fig. S3B. A breakdown of specific symptoms by affected RyR1 structural domain(s) is provided in Fig. 3B.

An AD/DN mode of inheritance was more frequently observed in participants with variant(s) that affected only the RyR1 CAC compared with only the CS $(97 \%$ versus $50 \%$ of cases respectively, $p<0.001)$. In four cases $(3,5$, 7 , and 11), multiple variants were identified that affected only the RyR1 CS, (Table 3). Bsol was the most frequently affected region (83\% of cases), in cases with only the RyR1 CS affected, followed by the RYR repeats 1 and 2 (RY1\&2), ( $25 \%$ of cases). Only one case (34) had multiple RYRI variants that affected only the CAC. In cases with variants that affected only the CAC, the pore region inclusive of the helical-bundle between $\mathrm{S} 2$ and $\mathrm{S} 3$ (S2S3), was affected most often (76\% of cases). In three related cases $(39,40,41)$ with a rhabdomyolysis clinical phenotype, the same $R Y R l$ variant (p.Asp4505His) affected a currently unresolved region between amino acid residues 4354-4631 [64]. In cases with variants that affected both RyR1 domains, Bsol within the CS was the most frequently affected region (84\% of cases).

Cases with variants affecting only the CS had lower scores for MFM-32 dimension 2 (axial and proximal motor function), when compared to cases with only the CAC affected, after adjustment for multiple comparisons [93.1 (13.2)\% versus 100 (1.4)\% respectively, $p<0.001$, Fig. 5a]. There was no significant difference in percent predicted maximal effort PFTs according to affected RyR1 domain(s), Fig. 5b. Yet cases, with variant(s) affecting only the RyR1 CS, achieved a significantly lower mean percent predicted SVC when compared to cases with variants affecting only the RyR1 CAC, after adjustment for multiple comparisons $(69.5 \pm 17.3 \%$ versus $87.0 \pm 18.0 \%$ respectively, $p=0.03)$, Fig. 5b. A greater proportion of cases with only the RyR1
CS affected, exhibited moderate respiratory insufficiency compared to cases with only the RyR1 CAC affected (40\% versus $3 \%$ respectively, $p=0.01$ ), Fig. S5c-e. There were no other statistically significant differences between groups.

\section{Detailed variant mapping and analysis}

Detailed $R Y R I$ variant mapping is provided with possible structural consequence in Figs. S6-S39. Variant map analysis demonstrated that, in this cohort, affected residues in cases with mild clinical severity (labelled white, green, and orange in Fig. 4f, g) were predominantly clustered to the CAC and the top portion of the CS. Clinically severe cases (labelled red in Fig. 4f, g) were limited to the CS. Affected residues at the interface of distinct RyR1 regions are detailed in Fig. S40.

In AR cases with premature termination or deletion variants (cases 3, 5, 10, 11, 12, 44, and 47) nonfunctional protein is coded. These variants likely result in decreased protein production, via nonsense-mediated decay of mutant mRNA, as supported by prior reports (see Table 3 ). In some cases, a single missense substitution that is considered likely pathogenic occurs in the same individual expressed on the other allele. Two individuals (cases 44 and 47) had termination variants which affected a residue in either the CS or CAC, as well as additional single or multiple missense substitution variants that affected the opposite RyR1 domain and were expressed on the other allele. In these cases, the termination variant likely results in decreased RyR1 expression with variants on the other allele exacerbating the individual's phenotype via RyR1 dysfunction. Several other recessive cases had termination or deletion variants and/or multiple missense substitutions and/or a duplication variant (cases 5, 7, 42, 43, and 47). A detailed structure-function/phenotype review of these cases is provided within Supplementary Material. 
Fig. 2 Median (IQR) MFM-32 scores (a) and pulmonary function test values (b) by mode of inheritance. a Except for standing and transfers, participants with an AR mode of inheritance achieved a significantly lower median (IQR) percentage of maximum MFM-32 score across all other MFM-32 domains, when compared to $\mathrm{AD} / \mathrm{DN}$ cases [standing and transfers, $71.8(33.3) \%$ vs. 59.0 (27.6)\% $p=0.078$; axial and proximal motor function, 100.0 (19.1)\% vs. 97.2 (16.0)\% $p=0.017$; distal motor function, $95.2(4.8) \%$ vs. 92.9 (8.3) $\% p=0.046$; total score, $87.5(17.7) \%$ vs. $79.7(18.8) \%$ $p=0.037]$. There was no difference in pulmonary function parameters when compared by mode of inheritance (all, $p>0.05),\left({ }^{\circ}\right.$ and $*$ denote outliers)

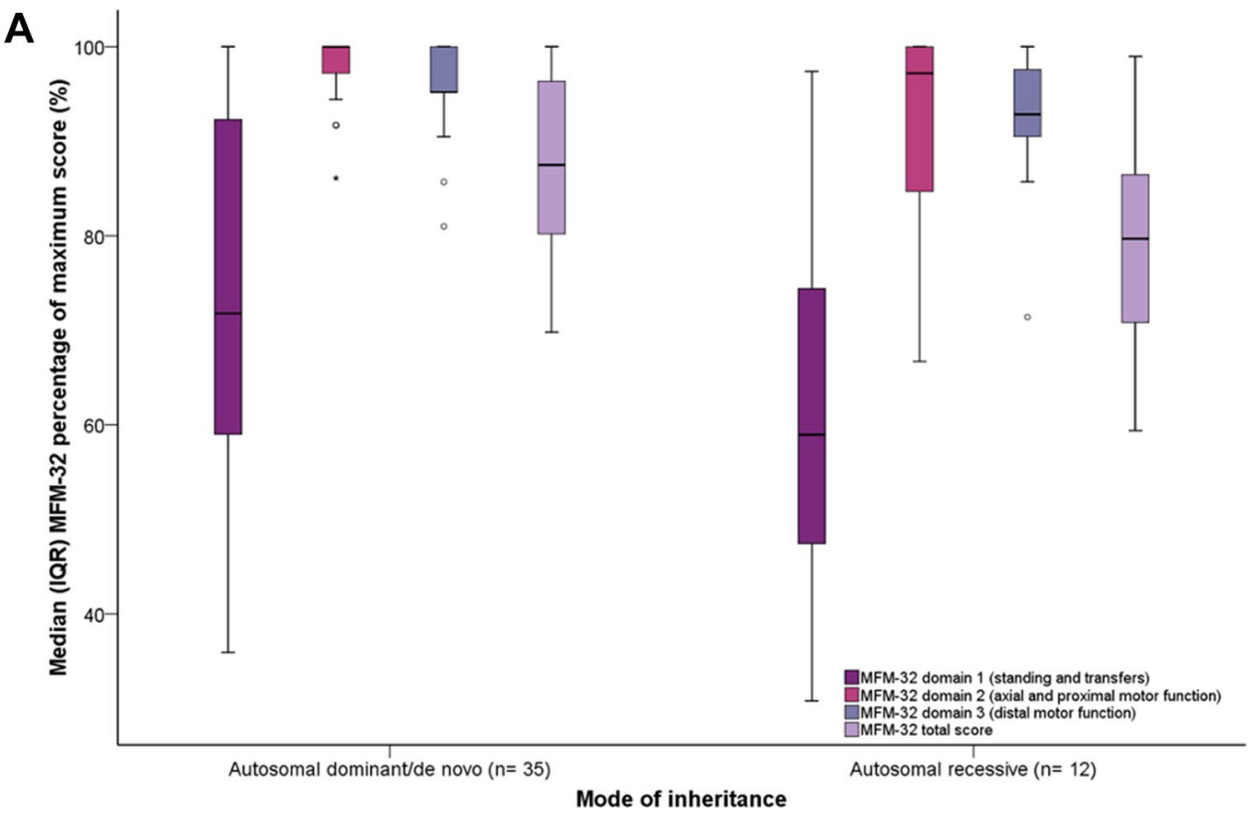

B

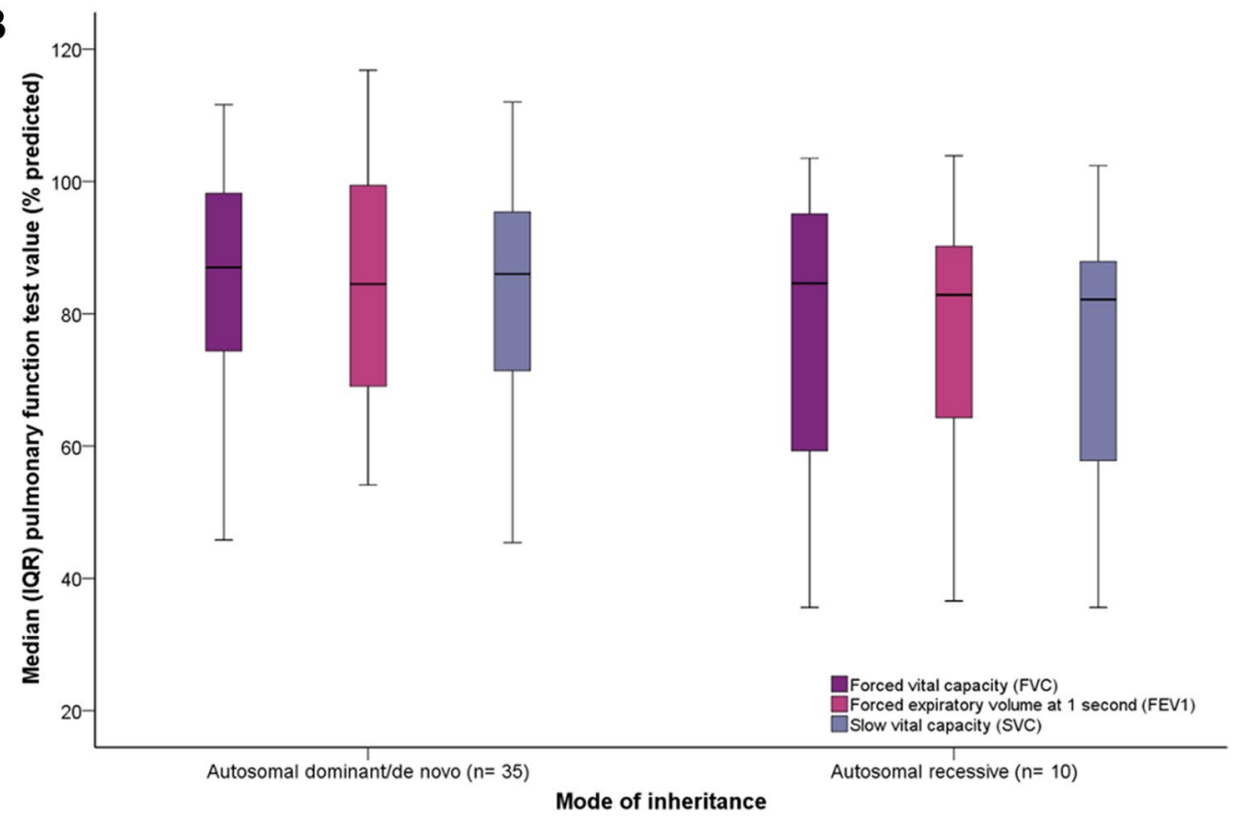

Mapping of variants on the RyR1 tetramer revealed that many localized to one plane in the outermost portion of the cytosolic shell (Fig. 4e, g). Herein, this will be referred to as the CS plane of interest and includes residues from the NTD (residues 1-392), Nsol (residues 393-627), Bsol (residues 2145-3613) and Csol (residues 3667-4174). Disease-associated variants in the Bsol and Csol were flanked on one side by the locations of variants in Nsol of the same subunit and on the other side by the site of variants in the NTD of the neighboring subunit. Thus, the CS plane of interest highlighted in Fig. 4e, consists of both intramolecular and intermolecular interactions between different domains.
We further evaluated the clinical severity scores assigned to variants within the CS plane of interest. In the interacting Bsol, Nsol, and NTD regions, clinical severity was associated with Grantham distance, which ranged from $>100$ for severe to $\sim 20$ for mild. Variants attributed to differing clinical severity (shown as red, orange and green in Fig. 4g) were distributed in clusters through the interdomain contact region, in an apparent gradient. Variants associated with a clinically severe phenotype were localized to Bsol in each subunit; those associated with an intermediate phenotype were found at the intermolecular contact between Nsol and NTD; and those associated with a mild phenotype were in intramolecular contacts between the Bsol and Nsol. 
Fig. 3 Bar charts of clinical symptom frequency by mode of inheritance (a) and affected RyR1 domain(s) (b) expressed as a percentage of cases. Statistically significant differences were as follows for $\mathrm{AD} / \mathrm{DN}$ versus AR categories, respectively; facial weakness $69 \%$ versus $100 \%, p=0.026$; neonatal hypotonia $6 \%$ versus $33 \%, p=0.034$; ophthalmoplegia/paresis $0 \%$ versus $42 \%, p<0.001$; ptosis $6 \%$ versus $42 \%, p=0.003$; and scapular winging $31 \%$ versus $67 \%, p=0.032$. When symptom frequency was compared by affected RyR1 domain(s), the only statistically significant difference, after adjustment for multiple comparisons, was in ophthalmoplegia/paresis between CS versus CAC, $25 \%$ versus $0 \%, p=0.005$ and both domains versus CAC, $33 \%$ versus $0 \%, p=0.001$. Differences in symptom frequency for all other symptoms, by mode of inheritance and affected RyR1 structural domain(s), were not significant, $p>0.05$
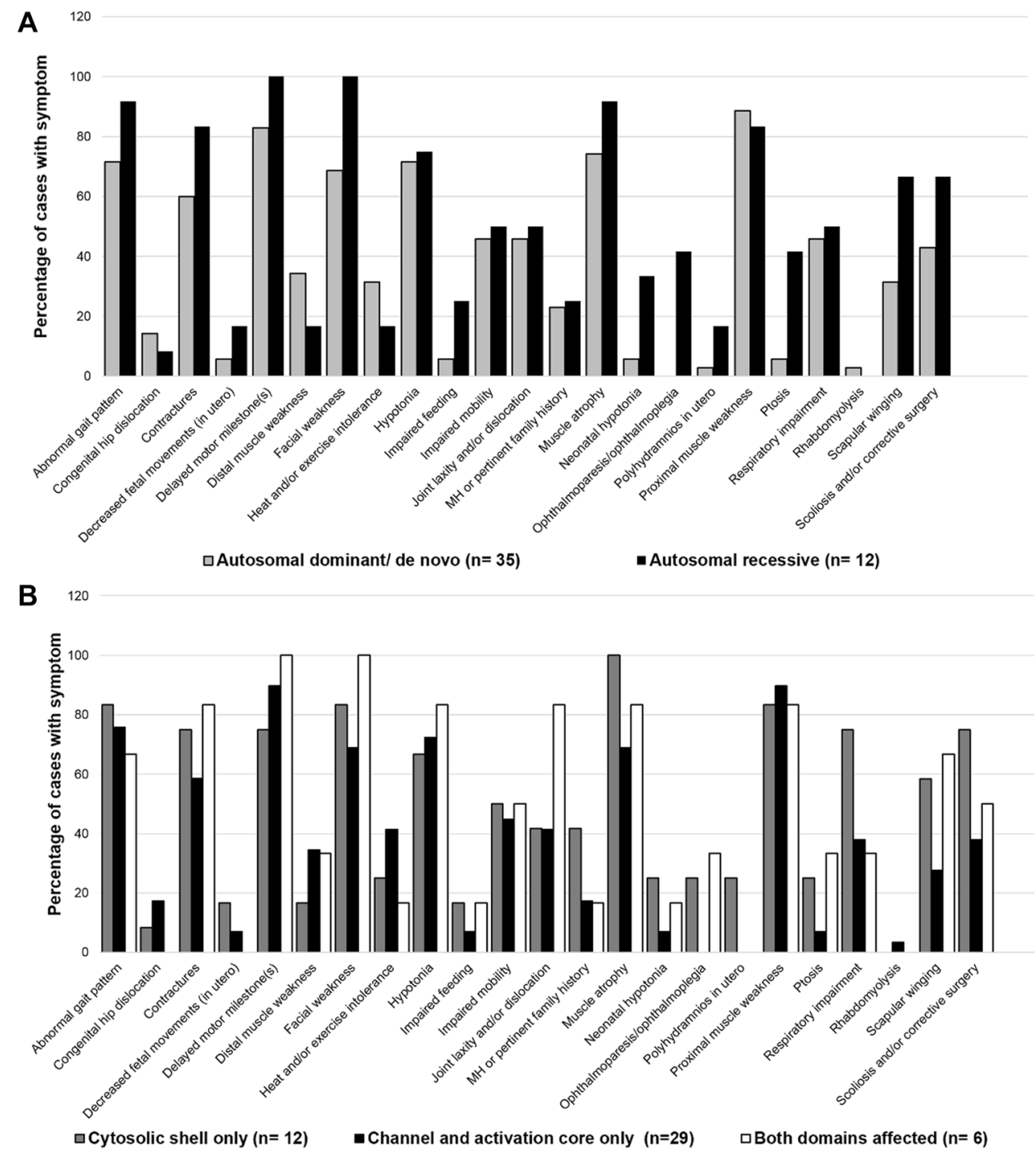

In this cohort, RYRI variants localized to the CAC along three horizontal planes (Fig. S41), each of which was associated with an average clinical severity score of 3. Herein, these will be referred to as CAC planes of interest 1, 2 and 3, respectively. All variants discussed in this domain were localized to inter-subunit contact regions. As such, variants form a ring and are cooperative. CAC plane of interest 1 included sites where luminal loops connect to the pore [variant (clinical severity score); Met4875Val (4), Glu4911Lys (2), Arg4861His (3), and Arg4893Gln (4)]. CAC plane of interest 2 lies in the $\mathrm{Ca}^{2+}$ entry pore [variant (clinical severity score); Ala4894Asp (4), Ile4898Thr (2), and Phe4921Leu (2)]. CAC plane of interest 3 is located where the SR membrane region transitions into the cytosol and includes major structural elements [variant (clinical severity score); Leu4936Arg (4), Ala4940Thr (2), Gly4820Arg (4), and Met4840Arg (0)].

\section{Discussion}

Clinical manifestations encompassed by the RYRI-RD disease spectrum are notoriously diverse. Nevertheless, we corroborate genotype-phenotype correlations and, through variant mapping to the latest cryo-EM RyR1 structure, elucidate structural regions (CS plane of interest, and CAC planes of interest 1,2, and 3) that may be important in determining clinical phenotype.

In this cohort, variants in AR cases were dispersed throughout the $R Y R 1$ coding region; in accordance with prior reports $[2,93]$. Due to the limited number of AR cases in this cohort, we cannot reject the null hypothesis that there is no difference in clinical severity by mode of inheritance. Nonetheless, the trend in this study is consistent with previous studies that report AR cases as being 
A

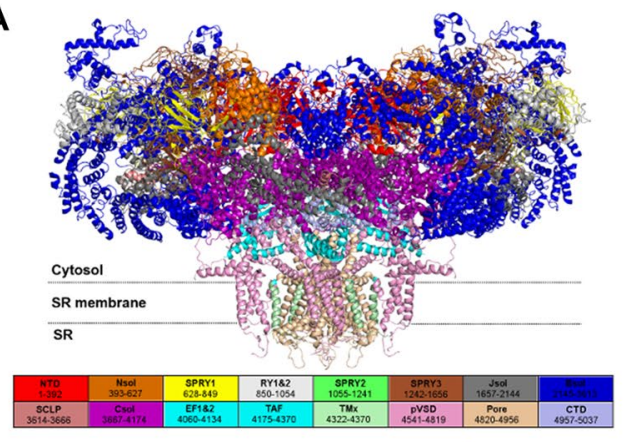

B

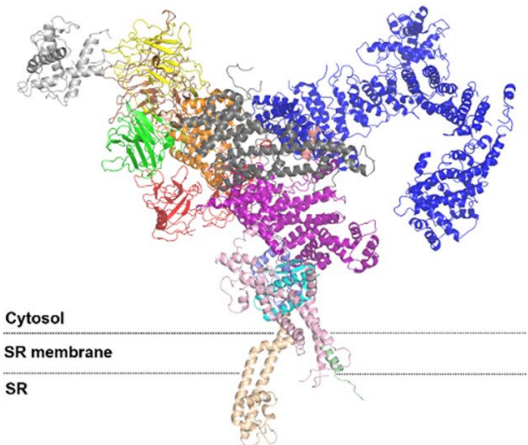

C

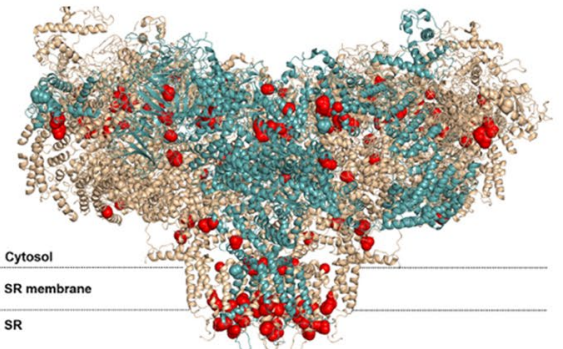

D

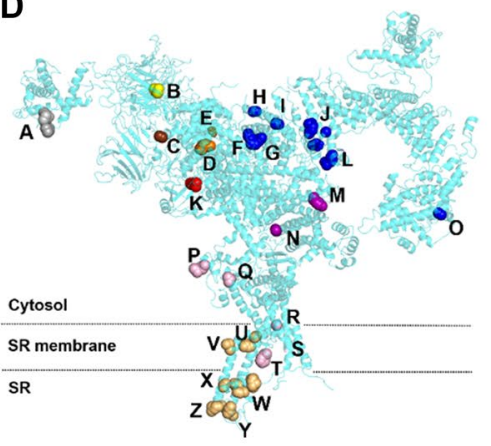

$\mathbf{F}$

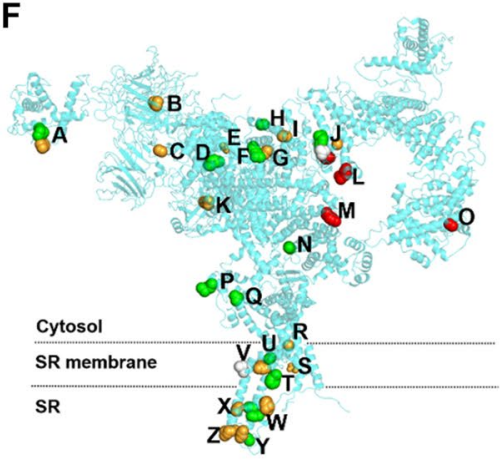

E

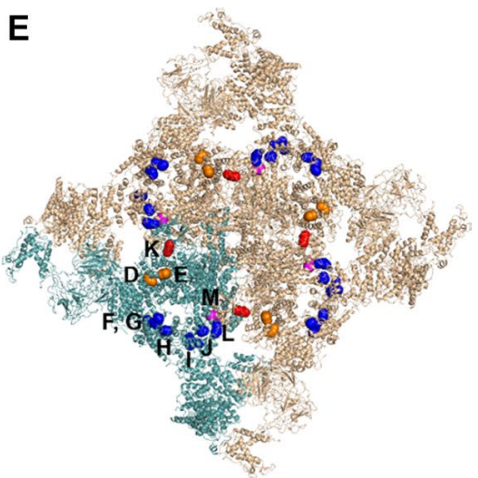

G

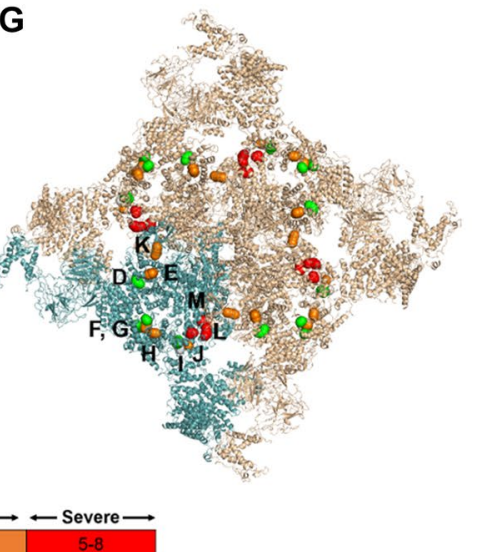

Fig. 4 a-g Variants mapped to the high resolution cryo-EM mammalian (rabbit) RyR1 structure. Letters a-g correspond to specific, affected RyR1 residues. Lettering is consistent between panels. a Topographical image of the RyR1 tetrameric structure with each structural region assigned a unique color. b Topographical image of a single RyR1 monomer with each structural region assigned a unique color. c RyR1 protein structure is shown with a single tetrameric subunit highlighted in teal. Each variant is represented by a sphere which includes the whole side chain of the affected residue. Lettering d-g identify affected RyR1 residues: (A, p.Arg1043Cys/ rabbit p.Arg1044; p.Arg975Trp/rabbit p.Arg976), (B, p.Asp708Asn/ rabbit p.Asp709), (C, p.Arg1606His/rabbit p.Arg1607), (D, p.Arg530His/rabbit p.Arg531), (E, p.Met485Val/rabbit p.Leu486), (F, p.Arg2163His/rabbit Arg2163), (G, p.Thr2206Met/rabbit Thr2206), (H, p.Arg2224His/rabbit p.Arg2224), (I, p.Cys2233Arg/rabbit p.Cys2233), (J, p.Arg2336His/rabbit p.Arg2336; p.Asn2342Ser/rabbit p.Asn2342; p.Val2354del/rabbit p.Val2354; p.Gly2434Arg/rabbit p.Gly2434), (K, p.Arg109Trp/rabbit p.Arg110), (L, p.Arg2452Trp/ rabbit p.Arg2452), (M, p.Tyr3933Cys/rabbit Tyr3934), (N, p.Ser4028Leu/rabbit p.Ser4029), (O, p.Arg3366/rabbit p.Arg3366),

more clinically severe than $\mathrm{AD} / \mathrm{DN}$ cases $(25 \%$ versus $11 \%)[29,30]$. This may partially explain why, on average, AR cases were diagnosed over ten years earlier than $\mathrm{AD} / \mathrm{DN}$ cases, in this cohort. In contrast to AR cases and as expected, RYRl variants inherited in an $\mathrm{AD} / \mathrm{DN}$
(P, p.Arg4737Gln/rabbit p.Arg4736), (Q, p.Thr4709Met/rabbit p.Thr4708), (R, p.Gly4820Arg/rabbit p.Gly4819), (S, p.Asn4575Thr/ rabbit p.Asn4574), (T, p.Phe4808Asn/rabbit p.Phe4807), (U, p.Leu4936Arg/rabbit p.Leu4935; Ala4940Thr/rabbit p.Ala4939), (V, p.Met4840Arg/rabbit p.Met4839), (W, p.Arg4893Gln/rabbit p.Arg4892; p.Ala4894Asp/rabbit p.Ala4893; p.Ile4898Thr/rabbit p.Ile4897; p.Phe4921Leu/rabbit p.Phe4920), (X, p.Thr4853Ile/rabbit p.Thr4852), (Y, p.Met4875Val/rabbit p.Met4874; p.Glu4911Lys/rabbit p.Glu4910), (Z, p.Arg4861His/rabbit p.Arg4860). d, e Variants in each RyR1 region are assigned distinct colors, as detailed in $\mathbf{a}, \mathbf{b} . \mathbf{f}$, g Variant mapping with color coding for clinical severity as follows: mild (clinically mild; $0=$ white, $1-2=$ green, $3-4=$ orange. Clinically severe $\geq 5=$ red). Clinical severity scores for each specific variant/participant are provided in Table S3. e RyR1 CS plane of interest with a single monomer highlighted in teal. View is facing the SR from the cytosol and variant coloring is as defined in $\mathbf{a}, \mathbf{b}$. Variants are enriched to the Bsol. $\mathbf{f}$ RyR1 CS plane of interest with a single monomer in teal. Clinical severity coloring, for each variant, is as defined in c. View is facing the SR from the cytosol. Variants with the greatest clinical severity are localized to the Bsol

manner were enriched within established MH/CCD hot spot regions, particularly MH/CCD hot spot 3 [89]. Variants affecting the $\mathrm{C}$-terminal region, as defined by the latest cryo-EM RyR1 residue spans, were not identified in this cohort. 
Fig. 5 Median (IQR) MFM-32 scores and pulmonary function test values by affected RyR1 domain(s). A trend was observed for participants with only the CS affected, to exhibit lower median (IQR) percentage of maximum MFM-32 scores for each dimension including total score, a. This was deemed statistically significant for comparison of dimension 2 only (axial and proximal motor function), after adjustment for multiple comparisons (only the CS affected, 93.1 (13.2)\% versus only the CAC affected 100.0 (1.4)\% respectively, $p<0.001)$. There was no difference in percent predicted maximal effort PFTs according to affected RyR1 domain(s), b. Cases, with variant(s) that affected only the $\mathrm{CS}$, achieved a significantly lower percent predicted SVC when compared to cases with variants that affected only the CAC, after adjustment for multiple comparisons $(69.5 \pm 17.3 \%$ versus $87.0 \pm 18.0 \%$ respectively, $p=0.03), \mathbf{b}\left({ }^{\circ}\right.$ and * denote outliers)
A

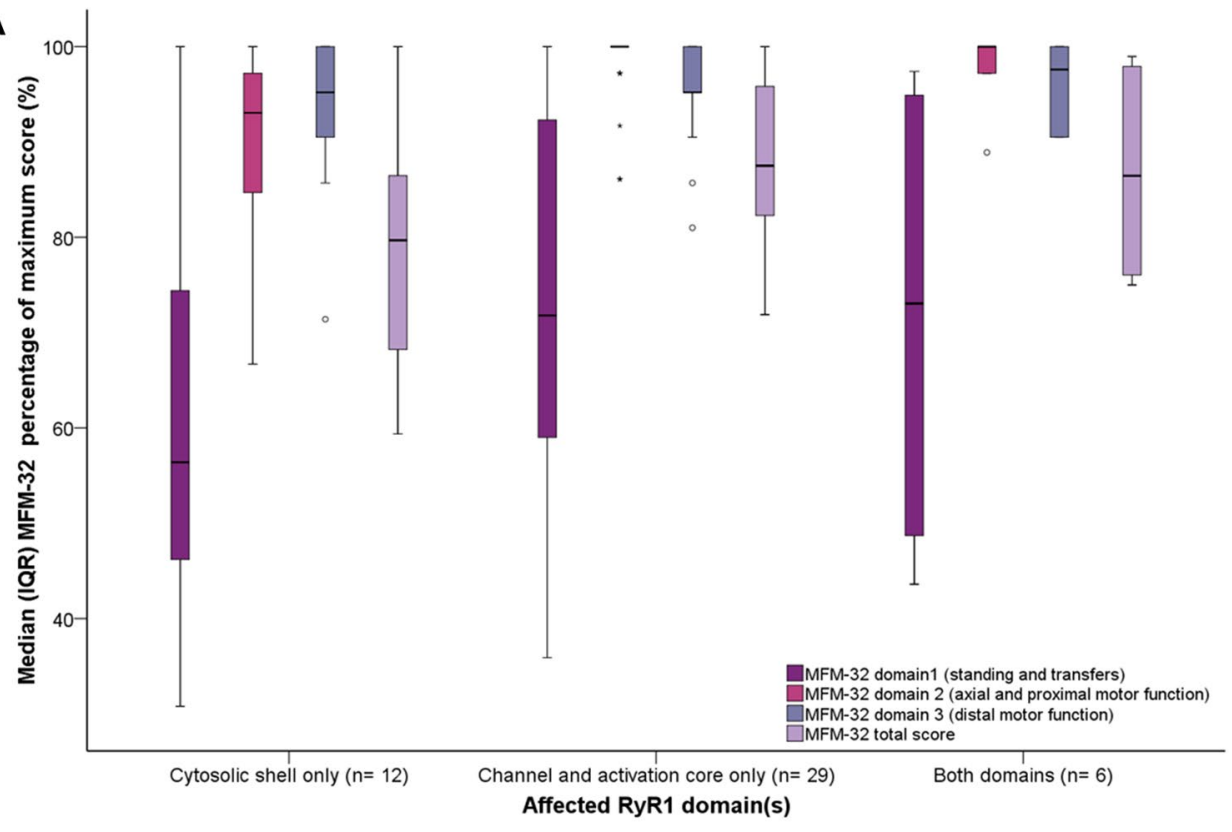

B

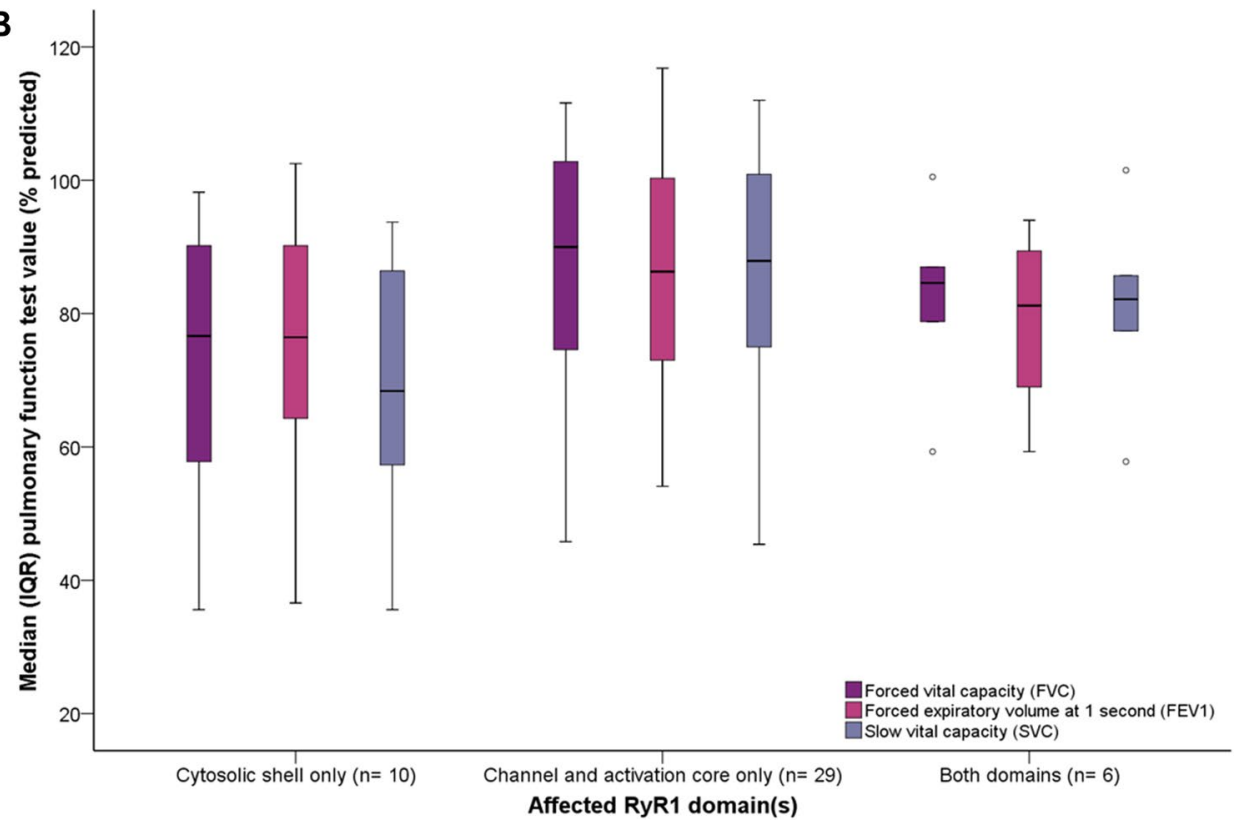

Massively parallel sequencing has been fundamental in achieving earlier $R Y R I$-RD diagnoses. Indeed, study participants born before the advent of this technology in 2004 were typically diagnosed as adults whereas those born after 2004 were generally diagnosed in early childhood, which underscores the utility of high-throughput sequencing technologies for this rare disease [16]. The ability to achieve an early RYRI-RD diagnosis has been further aided by the development of multi-gene congenital myopathy panels which, due to greater availability and decreased cost, should be considered the standard approach when seeking to confirm a specific genetic etiology [54]. Although histopathologic features have been used to define RYRI-RD subtypes, these features are variable over time and there is considerable overlap among categories, such as $\mathrm{MmD}$, CNM, and CRM [86]. Such overlap was evident in this study as $31 \%$ of participants with biopsy reports $(n=26)$ received inconclusive or non-specific histopathologic diagnoses. Our results further support a genetics-led diagnostic approach for congenital neuromuscular disorders.

The clinical findings in family 14 (cases 17-18, p.Ala4940Thr) and family 18 (cases 30-31, p.Ala4894Asp) reinforce the concept of variable expressivity in RYRI-RD. Indeed clinical manifestations were not consistent among family members despite having identical $R Y R I$ variants. This intrafamilial phenotypic variability in $R Y R I-\mathrm{RD}$ 
highlights the importance of personalizing care plans, even among related individuals with an identical genetic etiology. Undetected variants and presence of genetic modifiers may contribute to intrafamilial phenotypic variability however parental mosaicism may also offer a potential explanation for inter-generational phenotypic variability within families [47]. Our clinical findings expand the clinical heterogeneity associated with the p.Ile4898Thr variant, previously associated with moderate, severe and lethal phenotypes. In this cohort, two related individuals with a comparably mild phenotype (clinical severity score of 2 ) expressed this variant.

In family 30 , the mother reported a history of recurrent rhabdomyolysis which was accompanied by exercise intolerance and myalgia that both male offspring also exhibited. Of note, the p.Asp4505His variant has been previously implicated in a fatal non-pharmacologic induced $\mathrm{MH}$ episode, late-axial myopathy, and idiopathic hyperCKemia with MHS [20, 41, 44]. This reinforces the importance of detecting $R Y R 1$ variants, even in those with only mild myopathyrelated symptoms, as such individuals can still be at risk.

In this cohort, in utero and neonatal manifestations, with the exception of congenital hip dislocation, were associated with AR cases. In families with a medical history pertinent for congenital myopathy, this observation may become an important component of the RYRI-RD differential workup, by enabling families to prepare and clinical teams to counsel for an infant that could emerge to be on the severe end of the RYRl-RD spectrum of disease.

A greater proportion of cases, with variant(s) that affected only the RyR 1 CS, were clinically severe when compared to cases with variant(s) that only affected the RyR1 CAC yet there was no difference in the proportion of clinically severe cases by mode of inheritance. These findings may reflect limitations of tools currently available to assess clinical severity in the RYRI-RD population. Focusing on two facets of the disease, ambulation and respiratory function [2], may lead to an underestimation of disease severity when additional factors such as feeding difficulties, eye involvement and degree of scoliosis also contribute. As such, development of a multifacted, validated clinical severity assessment tool for congenital neuromuscular disorders would undoubtedly strengthen future studies.

Strengths of this study include the use of robust measures of motor function (MFM-32), respiratory function (PFTs in accordance with ATS guidelines), and a single clinician administered physical examinations that minimized variability in participant reports. Non-ambulatory individuals and those $<7$ years of age were excluded from clinical trial participation and this may have prevented our analysis from capturing the genotype/structure-phenotype of individuals at the most severe end of the RYRI-RD disease spectrum. Nonetheless, we demonstrate, for the first time using a validated tool, that RYRI-RD affected individuals have greatest difficulty performing movements that involve standing and transfers and that this deficit is comparable regardless of the mode of inheritance. Moreover, in this cohort, AR cases had the greatest motor function impairment overall, owing to additional difficulties performing axial, proximal, and distal movements. The identification of variable motor deficits, by mode of inheritance, suggests that tailored interventions would likely be appropriate in exercise/physical therapybased clinical trials.

Cases with variants that affected only the RyR1 CS, achieved a significantly lower percent predicted SVC compared to cases with variants that affected only the CAC or both domains, indicating that variant location may, at least in part, dictate clinical phenotype. Those affected by neuromuscular disease often have difficulty sustaining the forced exhalation required for FVC and $\mathrm{FEV}_{1}$ measurement [32]. As such, SVC may provide a suitable alternative measure of respiratory function with adequate sensitivity to detect differences among RYRI-RD sub-groups. Furthermore, SVC may serve as a useful clinical trial endpoint, subject to successful validation studies.

Several variants with minor physico-chemical changes were still associated with an RYRI-RD clinical phenotype. This could indicate that such residues have a functional role or are important to nearby functional residues, such as p.Arg2163 being close to the proposed FKBP12 binding site (Fig. 4e, g, Letter F) and p.Ser4028 being nearby to the putative $\mathrm{Ca}^{2+}$ binding site (Fig. 4d, f, letter N) [13, 51, 65]. As a result, such residues may be less able to tolerate variations.

Structural regions included within the CS plane of interest (NTD, Nsol, Bsol, and Csol) are far apart in sequence, but close in 3D space in the context of the tetramer, allowing long-range cooperativity, consistent with the observation that variations in the CS can affect gating in the CAC [84]. Most variants in this plane fell within either MH/CCD hot spots 1 or 2 ( $n=3$ and $n=9$, respectively). Many of these variants that have been functionally characterized in vitro (5/9) result in $\mathrm{Ca}^{2+}$ leakage, highlighting the functional importance of the CS in allosteric gating of the channel. The p.Tyr3933Cys substitution in the CS plane of interest is located in an inter-domain interaction between the CS and the CAC, suggesting it may be involved in transmitting the signal for pore gating. Many variants within the CS plane of interest occur at positions that are exposed to solution, often in open cavities, suggesting these cavities have important roles in channel function. Indeed, recent biophysical simulation studies have revealed additional ion conduction pathways that permeate the lateral aspect of the RyR1 CS and may thereby enable lateral $\mathrm{Ca}^{2+}$ efflux into the cytoplasm [22].

It is possible that variants within CAC plane of interest 1 affect $\mathrm{Ca}^{2+}$ flux or selectivity at the vestibule adjoining the entry pore. Variants within CAC plane of interest 2 likely 
affect entry pore function. p.Ala4894Asp alters the charge distribution, while p.Ile4898Thr and p.Phe4921Leu affect the pore structure itself thereby impairing $\mathrm{Ca}^{2+}$ selectivity or conductance [56]. Within CAC plane of interest 3, Leu4936 contributes to $\alpha$ helix- $\alpha$ helix packing and is immediately adjacent to Ile4937, a critical channel gating residue. Indeed, it is the hydrophobic properties of Ile4937, that enable this residue to form a physical gate at the narrowest section of the pore preventing $\mathrm{Ca}^{2+}$ flux in the RyR1 closed state [85]. All other variants within this plane occur at regions where sharp turns of the helices are formed. These regions are important for defining the structure and electrostatic properties of the gating regions.

\section{Conclusion}

Our comprehensive analyses corroborate genotype-phenotype associations and identify new protein structure-phenotype correlations and structural planes of interest that warrant further investigation. Through structural assessment of patient-derived $R Y R I$ variants, we show that although both RyR1 domains function together to enable optimal SR $\mathrm{Ca}^{2+}$ efflux, variants affecting the CS were associated with a more severe clinical phenotype. In particular, variants within the CS plane of interest were enriched in the Bsol that is crucial for maintaining effective inter-subunit interactions and channel gating. We demonstrate that variant location likely dictates clinical severity, in combination with the mode of inheritance, and degree of physico-chemical disruption, at RyR1 regions sensitive to structural modification.

Acknowledgements The authors would like to express their gratitude to the RYRI-RD affected individuals who participated in the clinical trial from which data were obtained for this study. We would also like to acknowledge Drs. Lucy Forrest (NINDS, NIH), Kenneth Fischbeck (NINDS, NIH), and Joan Austin (Indiana University School of Nursing) for their detailed review of the manuscript.

Funding Intramural Program of the National Institute of Nursing Research (NINR), National Institutes of Health (NIH); NIH Clinical Center (Bench to Bedside Award).

\section{Compliance with ethical standards}

Conflicts of interest On behalf of all authors, the corresponding author states that there is no conflict of interest.

Ethical approval Study procedures were approved by a National Institutes of Health (NIH) Institutional Review Board, and all participants provided informed consent or assent, in accordance with the Declaration of Helsinki.

Open Access This article is distributed under the terms of the Creative Commons Attribution 4.0 International License (http://creat ivecommons.org/licenses/by/4.0/), which permits unrestricted use, distribution, and reproduction in any medium, provided you give appropriate credit to the original author(s) and the source, provide a link to the Creative Commons license, and indicate if changes were made.

\section{References}

1. AlBakri A, Karaoui M, Alkuraya FS, Khan AO (2015) Congenital ptosis, scoliosis, and malignant hyperthermia susceptibility in siblings with recessive RYR1 mutations. J Am Assoc Pediatr Ophthalmol Strabismus 19:577-579

2. Amburgey K, Bailey A, Hwang JH, Tarnopolsky MA, Bonnemann CG, Medne L, Mathews KD, Collins J, Daube JR, Wellman GP, Callaghan B, Clarke NF, Dowling JJ (2013) Genotype-phenotype correlations in recessive RYR1-related myopathies. Orphanet J Rare Dis 8:117

3. Amburgey K, McNamara N, Bennett LR, McCormick ME, Acsadi G, Dowling JJ (2011) Prevalence of congenital myopathies in a representative pediatric united states population. Ann Neurol 70:662-665

4. Bai X-C, Yan Z, Wu J, Li Z, Yan N (2016) The Central domain of RyR1 is the transducer for long-range allosteric gating of channel opening. Cell Res 26:995-1006

5. Bannister ML, Hamada T, Murayama T, Harvey PJ, Casarotto MG, Dulhunty AF, Ikemoto N (2007) Malignant hyperthermia mutation sites in the Leu2442-Pro2477 (DP4) region of RyR1 (ryanodine receptor 1) are clustered in a structurally and functionally definable area. Biochem J 401:333-339

6. Berman HM, Westbrook J, Feng Z, Gilliland G, Bhat TN, Weissig H, Shindyalov IN, Bourne PE (2000) The protein data bank. Nucleic Acids Res 28:235-242

7. Bevilacqua JA, Monnier N, Bitoun M, Eymard B, Ferreiro A, Monges S, Lubieniecki F, Taratuto AL, Laquerriere A, Claeys KG, Marty I, Fardeau M, Guicheney P, Lunardi J, Romero NB (2011) Recessive RYR1 mutations cause unusual congenital myopathy with prominent nuclear internalization and large areas of myofibrillar disorganization. Neuropathol Appl Neurobiol 37:271-284

8. Blackburn PR, Selcen D, Gass JM, Jackson JL, Macklin S, Cousin MA, Boczek NJ, Klee EW, Dimberg EL, Kennelly KD, Atwal PS (2017) Whole exome sequencing of a patient with suspected mitochondrial myopathy reveals novel compound heterozygous variants in RYR1. Mol Genet Genomic Med 5:295-302

9. Brandom BW, Bina S, Wong CA, Wallace T, Visoiu M, Isackson PJ, Vladutiu GD, Sambuughin N, Muldoon SM (2013) Ryanodine receptor type 1 gene variants in the malignant hyperthermia-susceptible population of the United States. Anesth Analg 116:1078-1086

10. Colombo I, Scoto M, Manzur AY, Robb SA, Maggi L, Gowda V, Cullup T, Yau M, Phadke R, Sewry C, Jungbluth H, Muntoni F (2015) Congenital myopathies: Natural history of a large pediatric cohort. Neurology 84:28-35

11. Dai Y, Wei X, Zhao Y, Ren H, Lan Z, Yang Y, Chen L, Cui L (2015) A comprehensive genetic diagnosis of Chinese muscular dystrophy and congenital myopathy patients by targeted nextgeneration sequencing. Neuromuscul Disord NMD 25:617-624

12. Davis MR, Haan E, Jungbluth H, Sewry C, North K, Muntoni F, Kuntzer T, Lamont P, Bankier A, Tomlinson P, Sanchez A, Walsh P, Nagarajan L, Oley C, Colley A, Gedeon A, Quinlivan R, Dixon J, James D, Muller CR, Laing NG (2003) Principal mutation hotspot for central core disease and related myopathies in the C-terminal transmembrane region of the RYR1 gene. Neuromuscul Disord NMD 13:151-157 
13. des Georges A, Clarke OB, Zalk R, Yuan Q, Condon KJ, Grassucci RA, Hendrickson WA, Marks AR, Frank J (2016) Structural basis for gating and activation of RyR1. Cell 167:145-157.e117

14. Dlamini N, Voermans NC, Lillis S, Stewart K, Kamsteeg EJ, Drost G, Quinlivan R, Snoeck M, Norwood F, Radunovic A, Straub V, Roberts M, Vrancken AF, van der Pol WL, de Coo RI, Manzur AY, Yau S, Abbs S, King A, Lammens M, Hopkins PM, Mohammed S, Treves S, Muntoni F, Wraige E, Davis MR, van Engelen B, Jungbluth H (2013) Mutations in RYR1 are a common cause of exertional myalgia and rhabdomyolysis. Neuromuscul Disord NMD 23:540-548

15. Dowling JJ, Lillis S, Amburgey K, Zhou H, Al-Sarraj S, Buk SJ, Wraige E, Chow G, Abbs S, Leber S, Lachlan K, Baralle D, Taylor A, Sewry C, Muntoni F, Jungbluth H (2011) King-Denborough syndrome with and without mutations in the skeletal muscle ryanodine receptor (RYR1) gene. Neuromuscul Disord NMD 21:420-427

16. Fiszer D, Fisher NA, Carr IM, Shaw M-A, Hopkins PM (2014) Advantage from massive parallel sequencing of RYR1 and CACNA1S in diagnostics of malignant hyperthermia susceptibility. BMC Anesthesiol 14:A13

17. Galli L, Orrico A, Lorenzini S, Censini S, Falciani M, Covacci A, Tegazzin V, Sorrentino V (2006) Frequency and localization of mutations in the 106 exons of the RYR1 gene in 50 individuals with malignant hyperthermia. Hum Mutat 27:830

18. Girard T, Urwyler A, Censier K, Mueller CR, Zorzato F, Treves S (2001) Genotype-phenotype comparison of the Swiss malignant hyperthermia population. Hum Mutat 18:357-358

19. Grantham R (1974) Amino acid difference formula to help explain protein evolution. Science 185:862-864

20. Groom L, Muldoon SM, Tang ZZ, Brandom BW, Bayarsaikhan M, Bina S, Lee HS, Qiu X, Sambuughin N, Dirksen RT (2011) Identical de novo mutation in the type 1 ryanodine receptor gene associated with fatal, stress-induced malignant hyperthermia in two unrelated families. Anesthesiology 115:938-945

21. Haugen T, Toft M, Muller CR, Aasly J (2005) Malignant hyperthermia - a hereditary and potentially life-threatening condition. Tidsskrift for den Norske laegeforening: tidsskrift for praktisk medicin, ny raekke 125:2792-2794

22. Heinz LP, Kopec W, de Groot BL, Fink RHA (2018) In silico assessment of the conduction mechanism of the ryanodine receptor 1 reveals previously unknown exit pathways. Sci Rep 8:6886

23. Hernandez-Lain A, Husson I, Monnier N, Farnoux C, Brochier G, Lacene E, Beuvin M, Viou M, Manere L, Claeys KG, Fardeau M, Lunardi J, Voit T, Romero NB (2011) De novo RYR1 heterozygous mutation (I4898T) causing lethal core-rod myopathy in twins. Eur J Med Genet 54:29-33

24. Hernández-Ochoa EO, Pratt SJP, Lovering RM, Schneider MF (2015) Critical role of intracellular RyR1 calcium release channels in skeletal muscle function and disease. Front Physiol 6:420

25. Hutchinson D, Whyte K (2008) Neuromuscular disease and respiratory failure. Pract Neurol 8:229-237

26. Hwang JH, Zorzato F, Clarke NF, Treves S (2012) Mapping domains and mutations on the skeletal muscle ryanodine receptor channel. Trends Mol Med 18:644-657

27. Illingworth MA, Main M, Pitt M, Feng L, Sewry CA, Gunny R, Vorstman E, Beeson D, Manzur A, Muntoni F, Robb SA (2014) RYR1-related congenital myopathy with fatigable weakness, responding to pyridostigimine. Neuromuscul Disord NMD 24:707-712

28. Johannsen S, Treves S, Muller CR, Mogele S, Schneiderbanger D, Roewer N, Schuster F (2016) Functional characterization of the RYR1 mutation p.Arg4737Trp associated with susceptibility to malignant hyperthermia. Neuromuscul Disord NMD 26:21-25

29. Jungbluth H (2007) Central core disease. Orphanet J Rare Dis 2:25
30. Jungbluth H (2007) Multi-minicore disease. Orphanet J Rare Dis $2: 31$

31. Jungbluth H, Treves S, Zorzato F, Sarkozy A, Ochala J, Sewry C, Phadke R, Gautel M, Muntoni F (2018) Congenital myopathies: disorders of excitation-contraction coupling and muscle contraction. Nat Rev Neurol 14:151-167

32. Katirji B, Kaminski HJ, Ruff RL (2014) Neuromuscular disorders in clinical practice. Springer, New York, pp 79-88

33. Kraeva N, Heytens L, Jungbluth H, Treves S, Voermans N, Kamsteeg E, Ceuterick-de Groote C, Baets J, Riazi S (2015) Compound RYR1 heterozygosity resulting in a complex phenotype of malignant hyperthermia susceptibility and a core myopathy. Neuromuscul Disord NMD 25:567-576

34. Kraeva N, Zvaritch E, Rossi AE, Goonasekera SA, Zaid H, Frodis W, Kraev A, Dirksen RT, MacLennan DH, Riazi S (2013) Novel excitation-contraction uncoupled RYR1 mutations in patients with central core disease. Neuromuscul Disord NMD 23:120-132

35. Laszlo G (2006) Standardisation of lung function testing: helpful guidance from the ATS/ERS task force. Thorax 61:744-746

36. Lavezzi WA, Capacchione JF, Muldoon SM, Sambuughin N, Bina S, Steele D, Brandom BW (2013) Case report: death in the emergency department: an unrecognized awake malignant hyperthermia-like reaction in a six-year-old. Anesth Analg 116:420-423

37. Lee CS, Hanna AD, Wang H, Dagnino-Acosta A, Joshi AD, Knoblauch M, Xia Y, Georgiou DK, Xu J, Long C, Amano H, Reynolds C, Dong K, Martin JC, Lagor WR, Rodney GG, Sahin E, Sewry C, Hamilton SL (2017) A chemical chaperone improves muscle function in mice with a RyR1 mutation. Nat Commun 8:14659

38. Lee JM, Rho SH, Shin DW, Cho C, Park WJ, Eom SH, Ma J, Kim DH (2004) Negatively charged amino acids within the intraluminal loop of ryanodine receptor are involved in the interaction with triadin. J Biol Chem 279:6994-7000

39. Levano S, Vukcevic M, Singer M, Matter A, Treves S, Urwyler A, Girard T (2009) Increasing the number of diagnostic mutations in malignant hyperthermia. Hum Mutat 30:590-598

40. Litman RS, Griggs SM, Dowling JJ, Riazi S (2018) Malignant hyperthermia susceptibility and related diseases. Anesthesiology 128:159-167

41. Løseth S, Voermans NC, Torbergsen T, Lillis S, Jonsrud C, Lindal S, Kamsteeg E-J, Lammens M, Broman M, Dekomien G, Maddison P, Muntoni F, Sewry C, Radunovic A, de Visser M, Straub V, van Engelen B, Jungbluth H (2013) A novel late-onset axial myopathy associated with mutations in the skeletal muscle ryanodine receptor (RYR1) gene. J Neurol 260:1504-1510

42. Lynch PJ, Tong J, Lehane M, Mallet A, Giblin L, Heffron JJA, Vaughan P, Zafra G, MacLennan DH, McCarthy TV (1999) A mutation in the transmembrane/luminal domain of the ryanodine receptor is associated with abnormal $\mathrm{Ca}^{2+}$ release channel function and severe central core disease. Proc Natl Acad Sci 96:4164-4169

43. Magee KR, Shy GM (1956) A new congenital non-progressive myopathy. Brain 79:610-621

44. Malandrini A, Orrico A, Gaudiano C, Gambelli S, Galli L, Berti G, Tegazzin V, Dotti MT, Federico A, Sorrentino V (2008) Muscle biopsy and in vitro contracture test in subjects with idiopathic HyperCKemia. Anesthesiology 109:625-628

45. Manning BM, Quane KA, Ording H, Urwyler A, Tegazzin V, Lehane M, O’Halloran J, Hartung E, Giblin LM, Lynch PJ, Vaughan P, Censier K, Bendixen D, Comi G, Heytens L, Monsieurs K, Fagerlund T, Wolz W, Heffron JJ, Muller CR, McCarthy TV (1998) Identification of novel mutations in the ryanodinereceptor gene (RYR1) in malignant hyperthermia: genotype-phenotype correlation. Am J Hum Genet 62:599-609

46. Marchant CL, Ellis FR, Halsall PJ, Hopkins PM, Robinson RL (2004) Mutation analysis of two patients with hypokalemic 
periodic paralysis and suspected malignant hyperthermia. Muscle Nerve 30:114-117

47. Marks S, van Ruitenbeek E, Fallon P, Johns P, Phadke R, Mein R, Mohammed S, Jungbluth H (2018) Parental mosaicism in RYR1related central core disease. Neuromuscul Disord 28:422-426

48. Matthews E, Neuwirth C, Jaffer F, Scalco RS, Fialho D, Parton M, Raja Rayan D, Suetterlin K, Sud R, Spiegel R, Mein R, Houlden H, Schaefer A, Healy E, Palace J, Quinlivan R, Treves S, Holton JL, Jungbluth H, Hanna MG (2018) Atypical periodic paralysis and myalgia: a novel RYR1 phenotype. Neurology 90:e412-e418

49. McCarthy TV, Quane KA, Lynch PJ (2000) Ryanodine receptor mutations in malignant hyperthermia and central core disease. Hum Mutat 15:410-417

50. Meissner G (2017) The structural basis of ryanodine receptor ion channel function. J Gen Physiol 149:1065-1089

51. Murayama T, Ogawa H, Kurebayashi N, Ohno S, Horie M, Sakurai T (2018) A tryptophan residue in the caffeine-binding site of the ryanodine receptor regulates $\mathrm{Ca}^{2+}$ sensitivity. Commun Biol 1:98

52. Ngo VA, Perissinotti LL, Miranda W, Chen SRW, Noskov SY (2017) Mapping ryanodine binding sites in the pore cavity of ryanodine receptors. Biophys J 112:1645-1653

53. North KN, Wang CH, Clarke N, Jungbluth H, Vainzof M, Dowling JJ, Amburgey K, Quijano-Roy S, Beggs AH, Sewry C, Laing NG, Bönnemann CG (2014) Approach to the diagnosis of congenital myopathies. Neuromuscul Disord NMD 24:97-116

54. Oliveira J, Gonçalves A, Taipa R, Melo-Pires M, Oliveira ME, Costa JL, Machado JC, Medeiros E, Coelho T, Santos M, Santos R, Sousa M (2016) New massive parallel sequencing approach improves the genetic characterization of congenital myopathies. J Hum Genet 61:497

55. Parker R, Schiemann AH, Langton E, Bulger T, Pollock N, Bjorksten A, Gillies R, Hutchinson D, Roxburgh R, Stowell KM (2017) Functional characterization of C-terminal ryanodine receptor 1 variants associated with central core disease or malignant hyperthermia. J Neuromuscul Dis 4:147-158

56. Ramachandran S, Serohijos AW, Xu L, Meissner G, Dokholyan NV (2009) A structural model of the pore-forming region of the skeletal muscle ryanodine receptor (RyR1). PLoS Comput Biol 5:e1000367

57. Rebbeck RT, Nitu FR, Rohde D, Most P, Bers DM, Thomas DD, Cornea RL (2016) S100A1 protein does not compete with calmodulin for ryanodine receptor binding but structurally alters the ryanodine receptor-calmodulin complex. J Biol Chem 291:15896-15907

58. Richter M, Schleithoff L, Deufel T, Lehmann-Horn F, Herrmann-Frank A (1997) Functional characterization of a distinct ryanodine receptor mutation in human malignant hyperthermiasusceptible muscle. J Biol Chem 272:5256-5260

59. Robinson R, Carpenter D, Shaw MA, Halsall J, Hopkins P (2006) Mutations in RYR1 in malignant hyperthermia and central core disease. Hum Mutat 27:977-989

60. Roesl C, Sato K, Schiemann A, Pollock N, Stowell KM (2014) Functional characterisation of the $\mathrm{R} 2452 \mathrm{~W}$ ryanodine receptor variant associated with malignant hyperthermia susceptibility. Cell Calcium 56:195-201

61. Rueffert H, Olthoff D, Deutrich C, Meinecke CD, Froster UG (2002) Mutation screening in the ryanodine receptor 1 gene (RYR1) in patients susceptible to malignant hyperthermia who show definite IVCT results: identification of three novel mutations. Acta Anaesthesiol Scand 46:692-698

62. Rueffert H, Wehner M, Ogunlade V, Meinecke C, Schober R (2009) Mild clinical and histopathological features in patients who carry the frequent and causative malignant hyperthermia RyR1 mutation p.Thr2206Met. Clin Neuropathol 28:409-416
63. Sambuughin N, Holley H, Muldoon S, Brandom BW, de Bantel AM, Tobin JR, Nelson TE, Goldfarb LG (2005) Screening of the entire ryanodine receptor type 1 coding region for sequence variants associated with malignant hyperthermia susceptibility in the north american population. Anesthesiology 102:515-521

64. Samsó M (2017) A guide to the 3D structure of the ryanodine receptor type 1 by cryoEM. Protein Sci 26:52-68

65. Santulli G, Lewis D, des Georges A, Marks AR, Frank J (2018) Ryanodine receptor structure and function in health and disease. In: Harris JR, Boekema EJ (eds) Membrane protein complexes: structure and function. Springer Singapore, Singapore, pp 329-352

66. Sato K, Pollock N, Stowell KM (2010) Functional studies of RYR1 mutations in the skeletal muscle ryanodine receptor using human RYR1 complementary DNA. Anesthesiology 112:1350-1354

67. Schulz WL, Tormey CA, Torres R (2015) Computational approach to annotating variants of unknown significance in clinical next generation sequencing. Lab Med 46:285-289

68. Sei MDPDY, Sambuughin PDNyamkhishig N, Davis BSEdward J, Sachs D, Cuenca MDPhil B, Brandom MDBarbara W, Tautz MDT, Rosenberg MDH, Nelson PDThomas E, Muldoon MDSheila M (2004) Malignant hyperthermia in North America: genetic screening of the three hot spots in the type I ryanodine receptor gene. Anesthesiology 101:824-830

69. Shepherd S, Ellis F, Halsall J, Hopkins P, Robinson R (2004) RYR1 mutations in UK central core disease patients: more than just the C-terminal transmembrane region of the RYR1 gene. J Med Genet 41:e33

70. Snoeck M, van Engelen BG, Kusters B, Lammens M, Meijer R, Molenaar JP, Raaphorst J, Verschuuren-Bemelmans CC, Straathof CS, Sie LT, de Coo IF, van der Pol WL, de Visser M, Scheffer H, Treves S, Jungbluth H, Voermans NC, Kamsteeg EJ (2015) RYR1-related myopathies: a wide spectrum of phenotypes throughout life. Eur J Neurol 22:1094-1112

71. Stephens J, Schiemann AH, Roesl C, Miller D, Massey S, Pollock N, Bulger T, Stowell K (2016) Functional analysis of RYR1 variants linked to malignant hyperthermia. Temperature (Austin Tex) 3:328-339

72. Suman M, Sharpe JA, Bentham RB, Kotiadis VN, Menegollo M, Pignataro V, Molgo J, Muntoni F, Duchen MR, Pegoraro E, Szabadkai G (2018) Inositol trisphosphate receptor mediated $\mathrm{Ca}^{2+}$ signalling stimulates mitochondrial function and gene expression in core myopathy patients. Hum Mol Genet 27:2367-2382

73. Tammaro A, Di Martino A, Bracco A, Cozzolino S, Savoia G, Andria B, Cannavo A, Spagnuolo M, Piluso G, Aurino S, Nigro V (2011) Novel missense mutations and unexpected multiple changes of RYR1 gene in 75 malignant hyperthermia families. Clin Genet 79:438-447

74. Tavtigian SV, Greenblatt MS, Lesueur F, Byrnes GB (2008) In silico analysis of missense substitutions using sequence-alignment based methods. Hum Mutat 29:1327-1336

75. Tilgen N, Zorzato F, Halliger-Keller B, Muntoni F, Sewry C, Palmucci LM, Schneider C, Hauser E, Lehmann-Horn F, Muller CR, Treves S (2001) Identification of four novel mutations in the C-terminal membrane spanning domain of the ryanodine receptor 1: association with central core disease and alteration of calcium homeostasis. Hum Mol Genet 10:2879-2887

76. Todd EJ, Yau KS, Ong R, Slee J, McGillivray G, Barnett CP, Haliloglu G, Talim B, Akcoren Z, Kariminejad A, Cairns A, Clarke NF, Freckmann ML, Romero NB, Williams D, Sewry CA, Colley A, Ryan MM, Kiraly-Borri C, Sivadorai P, Allcock RJ, Beeson D, Maxwell S, Davis MR, Laing NG, Ravenscroft G (2015) Next generation sequencing in a large cohort of patients presenting with neuromuscular disease before or at birth. Orphanet J Rare Dis $10: 148$ 
77. Todd JJ, Razaqyar MS, Witherspoon JW, Lawal TA, Mankodi A, Chrismer IC, Allen C, Meyer MD, Kuo A, Shelton MS, Amburgey K, Niyazov D, Fequiere P, Bönnemann CG, Dowling JJ, Meilleur KG (2018) Novel variants in individuals with RYR1-related congenital myopathies: genetic, laboratory, and clinical findings. Front Neurol 9:118

78. Treves S, Scutari E, Robert M, Groh S, Ottolia M, Prestipino G, Ronjat M, Zorzato F (1997) Interaction of S100A1 with the $\mathrm{Ca}^{2+}$ release channel (ryanodine receptor) of skeletal muscle. Biochemistry 36:11496-11503

79. van Dijk EL, Auger H, Jaszczyszyn Y, Thermes C (2014) Ten years of next-generation sequencing technology. Trends Genet 30:418-426

80. Vuillerot C, Meilleur KG, Jain M, Waite M, Wu T, Linton M, Datsgir J, Donkervoort S, Leach ME, Rutkowski A, Rippert P, Payan C, Iwaz J, Hamroun D, Bérard C, Poirot I, Bönnemann CG (2014) English cross-cultural translation and validation of the neuromuscular score: a system for motor function classification in patients with neuromuscular diseases. Arch Phys Med Rehabil 95:2064-2070.e2061

81. Vuillerot C, Rippert P, Kinet V, Renders A, Jain M, Waite M, Glanzman AM, Girardot F, Hamroun D, Iwaz J, Ecochard R, Quijano-Roy S, Berard C, Poirot I, Bonnemann CG (2014) Rasch analysis of the motor function measure in patients with congenital muscle dystrophy and congenital myopathy. Arch Phys Med Rehabil 95:2086-2095

82. Wang CH, Bonnemann CG, Rutkowski A, Sejersen T, Bellini J, Battista V, Florence JM, Schara U, Schuler PM, Wahbi K, Aloysius A, Bash RO, Beroud C, Bertini E, Bushby K, Cohn RD, Connolly AM, Deconinck N, Desguerre I, Eagle M, EstournetMathiaud B, Ferreiro A, Fujak A, Goemans N, Iannaccone ST, Jouinot P, Main M, Melacini P, Mueller-Felber W, Muntoni F, Nelson LL, Rahbek J, Quijano-Roy S, Sewry C, Storhaug K, Simonds A, Tseng B, Vajsar J, Vianello A, Zeller R (2010) Consensus statement on standard of care for congenital muscular dystrophies. J Child Neurol 25:1559-1581

83. Wehner M, Rueffert H, Koenig F, Neuhaus J, Olthoff D (2002) Increased sensitivity to 4-chloro- $m$-cresol and caffeine in primary myotubes from malignant hyperthermia susceptible individuals carrying the ryanodine receptor $1 \mathrm{Thr} 2206 \mathrm{Met}$ (C6617T) mutation. Clin Genet 62:135-146

84. Wei R, Wang X, Zhang Y, Mukherjee S, Zhang L, Chen Q, Huang X, Jing S, Liu C, Li S, Wang G, Xu Y, Zhu S, Williams AJ, Sun F, Yin C-C (2016) Structural insights into $\mathrm{Ca}(2+)$-activated longrange allosteric channel gating of RyR1. Cell Res 26:977-994

85. Willegems KERG (2017) Membrane dynamics and calcium signaling. In: Krebs J (ed) Advances in experimental medicine and biology. Springer, Berlin, pp 179-204

86. Wilmshurst JM, Lillis S, Zhou H, Pillay K, Henderson H, Kress W, Muller CR, Ndondo A, Cloke V, Cullup T, Bertini E, Boennemann
C, Straub V, Quinlivan R, Dowling JJ, Al-Sarraj S, Treves S, Abbs S, Manzur AY, Sewry CA, Muntoni F, Jungbluth H (2010) RYR1 mutations are a common cause of congenital myopathies with central nuclei. Ann Neurol 68:717-726

87. Witherspoon JW, Meilleur KG (2016) Review of RyR1 pathway and associated pathomechanisms. Acta Neuropathol Commun 4:121

88. Witting N, Laforêt P, Voermans NC, Roux-Buisson N, Bompaire F, Rendu J, Duno M, Feillet F, Kamsteeg EJ, Poulsen NS, Dahlqvist JR, Romero NB, Fauré J, Vissing J, Behin A (2017) Phenotype and genotype of muscle ryanodine receptor rhabdomyolysismyalgia syndrome. Acta Neurol Scand 137:452-461

89. Wu S, Ibarra MC, Malicdan MC, Murayama K, Ichihara Y, Kikuchi H, Nonaka I, Noguchi S, Hayashi YK, Nishino I (2006) Central core disease is due to RYR1 mutations in more than $90 \%$ of patients. Brain 129:1470-1480

90. Yamamoto T, El-Hayek R, Ikemoto N (2000) Postulated role of interdomain interaction within the ryanodine receptor in $\mathrm{Ca}(2+)$ channel regulation. J Biol Chem 275:11618-11625

91. Yuchi Z, Yuen SM, Lau K, Underhill AQ, Cornea RL, Fessenden JD, Van Petegem F (2015) Crystal structures of ryanodine receptor SPRY1 and tandem-repeat domains reveal a critical FKBP12 binding determinant. Nat Commun 6:7947

92. Zalk R, Lehnart SE, Marks AR (2007) Modulation of the ryanodine receptor and intracellular calcium. Annu Rev Biochem 76:367-385

93. Zhou H, Jungbluth H, Sewry CA, Feng L, Bertini E, Bushby K, Straub V, Roper H, Rose MR, Brockington M, Kinali M, Manzur A, Robb S, Appleton R, Messina S, D’Amico A, Quinlivan R, Swash M, Muller CR, Brown S, Treves S, Muntoni F (2007) Molecular mechanisms and phenotypic variation in RYR1-related congenital myopathies. Brain 130:2024-2036

94. Zhou H, Lillis S, Loy RE, Ghassemi F, Rose MR, Norwood F, Mills K, Al-Sarraj S, Lane RJM, Feng L, Matthews E, Sewry CA, Abbs S, Buk S, Hanna M, Treves S, Dirksen RT, Meissner G, Muntoni F, Jungbluth H (2010) Multi-minicore disease and atypical periodic paralysis associated with novel mutations in the skeletal muscle ryanodine receptor (RYR1) gene. Neuromuscul Disord NMD 20:166-173

95. Zhou H, Yamaguchi N, Xu L, Wang Y, Sewry C, Jungbluth H, Zorzato F, Bertini E, Muntoni F, Meissner G, Treves S (2006) Characterization of recessive RYR1 mutations in core myopathies. Hum Mol Genet 15:2791-2803

96. Zullo A, Klingler W, De Sarno C, Ferrara M, Fortunato G, Perrotta G, Gravino E, Di Noto R, Lehmann-Horn F, Melzer W, Salvatore F, Carsana A (2009) Functional characterization of ryanodine receptor (RYR1) sequence variants using a metabolic assay in immortalized B-lymphocytes. Hum Mutat 30:E575-E590 